Año L. urtea

$125-2018$

Urtarrila-ekaina

Enero-junio

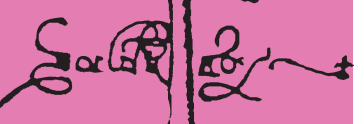

(n)

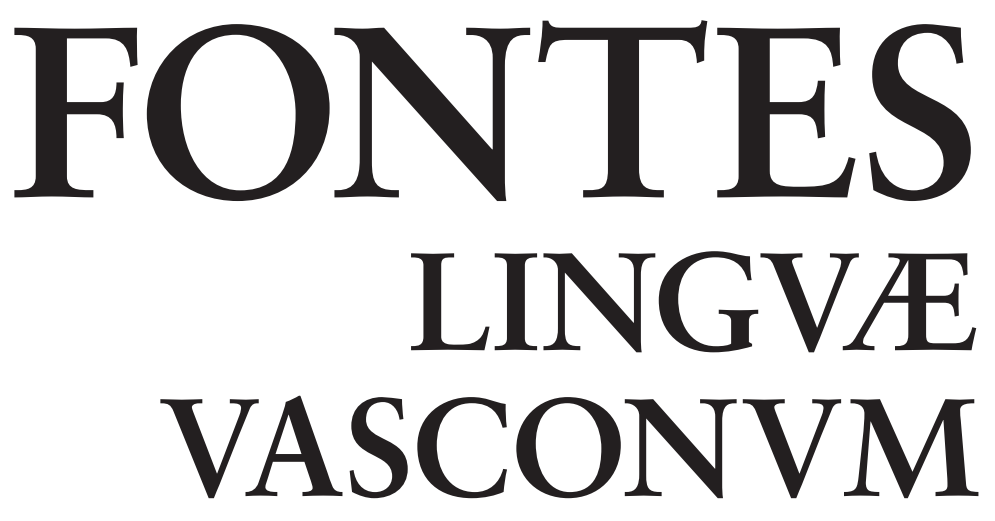

STVDIA ET DOCVMENTA

SEPARATA

\title{
Ezeztapenaren
}

hurrenkera euskal egitura perifrastikoetan:

hurbilpen diakroniko-tipologikoa

Iker SALABERRI

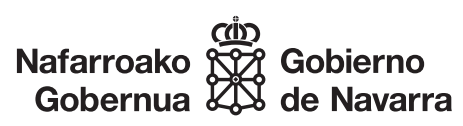

0000 


\section{Ezeztapenaren hurrenkera euskal egitura perifrastikoetan: hurbilpen diakroniko-tipologikoa}

El orden de la negación en las construcciones perifrásticas en euskera: un enfoque diacrónico-tipológico

The order of negation in Basque periphrastic constructions: a diachronic-typological approach

Iker SALABERRI

Nafarroako Unibertsitate Publikoa, UPNA/NUP

ikersalaberri@gmail.com

Patxi Salaberri Zaratiegiri eskerrak eman nahi nizkioke, artikuluaren gainean egindako iruzkin eta zuzenketa guztiengatik.

Jasotze data: 18/10/2017. Behin-behineko onartze data: 03/12/2017. Behin betiko onartze data: 19/02/2018. 


\section{LABURPENA}

Lan honen helburua euskarazko ezezko perpausetako aditz nagusiak eta laguntzaileak historian zehar izan duten hurrenkera aztertzea da. Hizkuntzaren historiako hainbat testuren hitz-hurrenkerari begiratuz, aditz nagusia - ezezkoaren marka - aditz laguntzailea ordena (ikusi ez zuen modukoa) perpaus nagusietan desagertzen eta mendekoetan gordetzen dela erakusten da, eta, aldi berean, desberdintasun horri azalpen tipologikoa emateko saioa egiten da. Ezeztapenaren hurrenkerari eragiten dioten zenbait faktoreren inguruan ere (perpaus mota, euskalkia etab.) hausnarketa egiten da.

Gako hitzak: Euskararen idatzizko historia; ezeztapena; egitura perifrastikoa; diakronia; tipologia.

\section{RESUMEN}

Este estudio tiene como objetivo investigar el desarrollo histórico del orden de los verbos principal y auxiliar en oraciones negativas en euskera. En el artículo se muestra, tras realizar un análisis del orden de palabras en textos históricos, que en las oraciones principales se pierde el orden en el que la partícula negativa va entre el verbo principal y el auxiliar (como en ikusi ez zuen), mientras que en las subordinadas dicho orden se mantiene. Se intenta explicar esta asimetría en términos tipológicos y se toman en consideración ciertos factores que afectan al orden de la negación, como el tipo de oración o el dialecto.

Palabras clave: Historia del euskera escrito; negación; construcción perifrástica; diacronía; tipología.

\section{ABSTRACT}

This study aims to investigate the historical development in Basque of the order of the main and auxiliary verb in negated clauses. By analyzing word order in a number of historical texts it is shown that the pattern according to which the negative particle follows the main verb and precedes the auxiliary (as in ikusi ez zuen) is lost in main clauses. At the same time, subordinate clauses are shown to preserve this pattern. An attempt is made to account for this asymmetry in typological terms. A number of factors that affect the order of negation, such as clause type and dialect, are also considered.

Keywords: History of written Basque; negation; periphrastic construction; diachrony; typology. 
1. SARRERA. 1.1. Ezeztapena egungo euskaran. 1.2. Ezeztapena euskararen historian. 1.3. Ezeztapena perpaus nagusietan eta mendekoetan. 2. EZEZTAPENAREN HURRENKERA HISTORIAN ZEHAR. 2.1. Ezeztapena literaturan. 2.1.1. Ezeztapena XVI. mendean. 2.1.2. Ezeztapena XVII. mendean. 2.1.3. Ezeztapena XVIII. mendean. 2.1.4. Ezeztapena XIX. mendean. 2.1.5. Ezeztapena XX. mendean. 2.2. Ezeztapena: datuen interpretazioa. 2.3. Ezeztapena zenbait faktoreren arabera. 2.3.1. Perpaus mota. 2.3.2. Euskalkia. 3. ONDORIOAK. 4. ERREFERENTZIAK.

\section{SARRERA}

Lan honen helburua ezezko perpausetako aditz nagusiak eta laguntzaileak historian zehar izan duten hurrenkera aztertzea da. Hainbat testuren hitz-hurrenkerari begiratuz, aditz nagusia - ezezko marka - aditz laguntzailea ordena (ikusi ez zuenen erakoa) perpaus nagusietan desagertzen eta mendeko perpausetan gordetzen dela erakusten da, eta desberdintasun honi azalpen tipologikoa emateko saioa egiten da. Xede hau kontuan izanik, 1.1 atalean ezezko egitura perifrastikoen ikuspegi sinkronikoa aurkezten da. 1.2 atalean, berriz, egitura hauen berauen ikuspegi diakronikoa erakusten da, eta euskararen historian ezezko egitura perifrastikoek jasan dituzten aldaketen inguruan idatzitakoen azterketa kritikoa egiten da. 1.3 atalean aztergai hartu diren perpaus motak definitzen dira, eta hauei buruzko aipu tipologikoa egiten. 2.1 atalean euskararen historiako hainbat testutako datuak bildu eta eztabaidatu ondoren, 2.2 eta 2.3 ataletan datu horiek interpretatu eta eragin diezaieketen hainbat faktoreren inguruan hausnarketa egiten da. Hirugarren atalean, azkenik, ondorioak ateratzen dira.

\subsection{Ezeztapena egungo euskaran}

Egungo euskaran, baiezko perpaus nagusietan, hitz-hurrenkera markatugabea aditz nagusia aditz laguntzailearen aurretik duena da (1a). Ezezkoetan, berriz, aditz nagusiak aditz laguntzaileari darraio (1b) (Laka, 1990, 27. or.; Hualde \& Ortiz de Urbina, 2003, 519, 559-561. or.). Gainera, ezezko perpaus nagusietan aditz laguntzailea aditz nagusiaren atzetik paratzeak esaldia agramatikal bihurtzea dakar (1c-d); ez, ordea, mendeko perpausetan (1e-f): 


$\begin{array}{ll}\text { (1) } & \text { Dirua ikusi dut } \\ \text { b. } & \text { Ez dut dirurik ikusi } \\ \text { c. } & { }^{*} \text { Ez dirurik ikusi dut }{ }^{1} \\ \text { d. } & \text { *Dirurik ikusi ez dut } \\ \text { e. } & \text { Dirurik ikusi ez dudalako } \\ \text { f. } & \text { Ez dudalako dirurik ikusi }\end{array}$

Perpaus nagusien eta mendekoen arteko desberdintasun hau azaltzeko De Rijkek (1969, 330. or.) hurrengo proposamena egiten du: mendeko perpausetan ezezko marka - aditz laguntzailea - aditz nagusia $\left(\mathrm{E}_{\mathrm{A}} \mathrm{A}_{\mathrm{L}}-\mathrm{A}_{\mathrm{N}}^{2}\right)$ hurrenkera Aux(iliary)-Movement delakoagatik sortzen da, hots, -la-z bestelako edozein atzizki daraman aditz laguntzaile orok nagusiari jarraitu behar dio; beraz, ( 2 a) bezalako esaldietan, aditz laguntzailea (da) aditz nagusiaren aurrean (etorri) ager daiteke, menderagailua bait- delako. Aldiz, (2b)-n aditz laguntzaileak -lako darama, eta horregatik ezin du aditz nagusiaren aurretik agertu (2c):

\section{(2) a. Ez dut ikusi, ez bait da etorri \\ b. Etorri ez delako ez dut ikusi \\ c. $\quad * E z$ delako etorri ez dut ikusi}

Perpaus nagusietan, berriz, Aux(iliary)-Movement nahitaezkoa da, hots, E- $\mathrm{A}_{\mathrm{L}}-\mathrm{A}_{\mathrm{N}}$ hurrenkera ezinbestekoa da halako perpausetan ${ }^{3}$. Azalpen honek balio sinkronikoa dauka, eta hizkuntzalaritza sortzaile-bihurtzailearen printzipioei jarraituz (Chomsky 1965, 128-147, 1986, 68) bi egitura hartzen ditu aintzat: sakoneko egitura (D(eep)Structure), sintaxi eragiketak osatu aurretik esaldiaren osagaiak sortzen direna, eta azaleko egitura (S(urface)-Structure), sintaxi eragiketen emaitza erakusten duena. De Rijken (1969, 331. or.) proposamenaren arabera, euskaraz sakoneko egituran hitz hurrenkera $A_{N}-A_{L}$ da (3a), eta ezeztapenak Aux-Movement eragiketa gauzatzea dakar (3b). Honek azaleko egituran $A_{L}-A_{N}$ sortzen du (3c):

1 Alabaina, (1c)-ren moduko esaldiak ez lokailutzat erabiltzean gramatikalak direla esan beharra dago: $E z$ dirurik ikusi dut, ez lanik egin dut. Ikus hurrengo atala ez lokailua ikerketa honetan nola tratatu den jakiteko.

2 Hemendik aurrera hurrengo laburdurak erabiliko dira: «E» = ezezko marka, « $\mathrm{A}_{\mathrm{N}} »=$ aditz nagusia, $« \mathrm{~A}_{\mathrm{L}}$ " = aditz laguntzailea, «(pn)» = perpaus nagusia, «(m)»= mendeko perpausa.

3 Aux(iliary)-Movement delakoa baiezko perpausetara ere zabal daiteke eta, horregatik, ezezko perpaus nagusietako aditz nagusia eta laguntzailea tokialdatzeko eragiketak baiezko perpaus nagusiei ere eragin diezaieke (De Rijk, 1969, 334. or.). Honen adibideak Iparraldeko euskalkietan izaten dira, Egun ogia erosi dutlegun dut erosi ogia moduko pareetan. Egun dut erosi ogia bezalako perpausetan galdegaiak (egun-ek) aditz nagusia eta laguntzailea lekualdatzea ahalbidetzen du (Lafitte, 1944, 47. or.; Ortiz de Urbina, 1987, 342-343. or.). Honen harira, De Rijkek (1969, 334. or.) iradokitzen du Iparraldeko euskalkietan Aux(iliary)-Movement delakoa baiezko perpaus nagusietan nahiz ezezkoetan egiteko aukera dagoela, baina Hegoaldean bakarrik ezezkoetan gauzatu daitekeela. Edozein modutan, Iparraldeko euskalkietako baiezko perpaus nagusietan aditz nagusia eta laguntzailea tokialdatzeko aukera berrikuntza dela dirudi: «[T]he testimony of older writers indicate [sic] that the modern system - or lack of system - is an innovation» (ibid.). Horrek ez luke, beraz, euskarazko ezeztapenaren ikerketa diakronikorako bestelako ondoriorik izan behar. Beste alde batetik, egungo euskaran Aux(iliary)-Movement delakoa mendeko perpausetan ez ezik, Ezagutuko ez dut ba!-ren moduko harridura perpausetan ere ez da gertatu: ezezko harridura perpausak esamolde finkoak, hots, fosilizatuak dira (Reguero-Ugarte, 2013, 435. or.). 
(3) a. Lehen urratsa: *Etorri ez da (sakoneko egitura, $A_{N}-A_{L}$ )

b. Bigarren urratsa: Aux-Movement (eragiketa sintaktikoa)

c. Hirugarren urratsa: Ez da etorri (azaleko egitura, $\mathrm{A}_{\mathrm{L}}-\mathrm{A}_{\mathrm{N}}$ )

Hizkuntzalaritza sortzaile-bihurtzailearen esparruko beste ikertzaile batzuek ere euskarazko ezeztapenaren antzeko azterketa proposatu dute ${ }^{4}$ (Goenaga, 1980; Ortiz de Urbina, 1987, 342-349. or.; Laka, 1990, 27-31. or.; 1991, 908-910. or.). Hurbilpen hau, nolanahi ere, gaur egungo euskarari dagokio. Hurrengo atalean erakutsiko den moduan, euskararen historian zehar edireten den ezeztapenaren hurrenkera ez da erabat egungo euskaran aurki daitekeena.

\subsection{Ezeztapena euskararen historian}

Euskararen historian zehar, ezezko egitura perifrastikoetan, batik bat lau konbinazio daude lekukotuta: ezezko marka - aditz laguntzailea - aditz nagusia perpaus nagusietan $\left(\mathrm{E}-\mathrm{A}_{\mathrm{L}}-\mathrm{A}_{\mathrm{N}}(\mathrm{pn})\right)(4 \mathrm{a}-\mathrm{b})$ zein mendekoetan $\left(\mathrm{E}-\mathrm{A}_{\mathrm{L}}-\mathrm{A}_{\mathrm{N}}(\mathrm{m})\right)(4 \mathrm{e})$, eta aditz nagusia - ezezko marka - aditz laguntzailea bai perpaus nagusietan $\left(\mathrm{A}_{\mathrm{N}}-\mathrm{E}-\mathrm{A}_{\mathrm{L}}(\mathrm{pn})\right)(4 \mathrm{c}, 4 \mathrm{~d}(?))$ eta bai mendekoetan $\left(\left(\mathrm{A}_{\mathrm{N}}-\mathrm{E}-\mathrm{A}_{\mathrm{L}}(\mathrm{m})\right)(4 \mathrm{f})\right.$ :

(4) a. Aytzetic mendecaceco onlacoac eztu sines escacen (Beriain, 1621, 93. or.)

b. $\quad$ Ni emen nayzala eçuen scribatu bear berçeri (Juan de Irañeta, 1549; Mitxelena, 1964, 59-60)

c. Gure eusquerac bazter oietan orrelaco guizaseme andien patu onic izan ez du (Kardaberatz, 1761b; Altuna \& Zulaika, 2004, 24. or.)

d. Guec ajutu eç dugu (Donemiliagako glosa, $\approx 1000$; Irigoien, 1975, 170. or.) ${ }^{5}$

e. Munduac balecusa eztuçula batere iuramẽturic eguiten (Axular, 1643, 265. or.)

f. Ascotan jarraituten dira bere oñean, gueroric guero andiagotuten ezpadira (Añibarro, 1803, 32. or.)

Aurreko atalean azaldu den moduan, gaurko euskaran (4c) bezalako hitz-hurrenkera agramatikala da perpaus nagusietan, baina ez, ordea, mendekoetan. (4c)-k erakusten duenez, hala ere, XVIII. mendeko euskaran bi hitz-ordenak, hots, (4a-b)-ren eta (4c)-ren modukoak ziren gramatikalak perpaus nagusietan. Horrek iradokitzen du gaur egungo euskaran perpaus nagusietan baitezpadakoa den Aux(iliary)-Movement arau sintaktikoa XVIII. mendean aukerakoa zela. Aipatutako gizaldiko euskararen eta

4 Alabaina, mendeko perpausetako ezeztapenaren hurrenkeraren analisia ez da horren sinplea, hemen aipatu ez diren bestelako faktore batzuek ere -hala nola aditza jokatua edo ez-jokatua izateak-, hitz ordenari eragiten baitiote (Etxepare \& Uribe-Etxebarria, 2009, 344. or.).

5 Ajutu hitzaren balioa ziurra ez denez (Irigoien, 1975, 170. or.), ezin da zalantzarik gabe baieztatu Donemiliagako glosa (4c) bezalakoa dela, hots, $\mathrm{A}_{\mathrm{N}}-\mathrm{E}-\mathrm{A}_{\mathrm{L}}(\mathrm{pn})$ hurrenkera islatzen duela. 
egungoaren arteko desberdintasun hori du ikerketa honek aztergai, izan ere ${ }^{6}$. Gainera, ez dago garbi euskararen historian $\mathrm{E}-\mathrm{A}_{\mathrm{L}}-\mathrm{A}_{\mathrm{N}}$ eta $\mathrm{A}_{\mathrm{N}}-\mathrm{E}-\mathrm{A}_{\mathrm{L}}$ hurrenkeren arteko aldakortasuna zer faktorek baldintzatzen duten, eta hau argitzeko saioa ere egingo da.

Ezezko egitura perifrastikoen bilakaera landu duten ikerketei begira, aipatzekoa da ez dagoela hau ikergai bakartzat hartu duen lanik, honetan zentratu denik. Ezeztapenaren hurrenkera orain arte iragaitzaz baizik ez da ukitu, hizkuntzaren beste alderdi batzuk landu bidenabar: adibidez euskararen oinarrizko hitz-hurrenkera (De Rijk, 1969, 330-334. or.; Mitxelena, 1978, 223-224. or.) eta euskalkien ezaugarriak (Lakarra, 1986, 655. or.) aztertzean, edo testuren baten edizioan (Lakarra, 1996, 254-255. or., 18. oin oharra). Mitxelenaren (1978, 223-224. or.) arabera, XVIII. eta XIX. mendeko Gipuzkoako idazleen artean bi joera ikus daitezke, hitz hurrenkerari zein bestelako kontuei dagokienez: alde batetik Agirre Asteasukoak ez du $\mathrm{A}_{\mathrm{N}}-\mathrm{E}_{-} \mathrm{A}_{\mathrm{L}}$ (pn) hurrenkera erabiltzen, bere idazkera herrikoiagoa delako, eta Lardizabalek berriz bai ${ }^{7}$, teorian eta gramatika arauemailean aritua delako:

En resumen, podría apuntarse [...] que en la gran tradición guipuzcoana [...] la que va más o menos de 1750 a 1850, aunque cuente después con valiosos epígonos que la prolongan, se manifiestan al menos dos tipos de narración, una, acaso más próxima a modelos populares, que hemos personificado en Aguirre, y otra más libresca, más gramatical, para la cual hemos tomado de cabeza de turco a Lardizabal (Mitxelena, 1978, 224. or.)

Honen harira, erraza da Lardizabalen lanetan $\mathrm{A}_{\mathrm{N}}-\mathrm{E}-\mathrm{A}_{\mathrm{L}}(\mathrm{pn})$ hurrenkera aurkitzea, (5a-b) pasartetxoetan, kasu; Agirre Asteasukoak, aldiz, bere garaiko ahozko euskaran ohikoa zen hurrenkera besterik ez du erabiltzen, nonbait, $(5 \mathrm{c}-\mathrm{d})$ lekukotasunetan esaterako:

(5) a. Anchume bat egundaño eman ez didazu (Lardizabal, 1908, 530. or.)

b. Zure semearen icenic ere mereci ez det (Lardizabal, 1908, 531. or.)

c. Baña etcion iñorc ematen nai adiña (Agirre, 1978)

d. Baña ez dira contentatu Erregue berac onembesterequin (Agirre, 1978)

Baieztapen hau garrantzitsua da, XIX. mendearen erdialderako $A_{N}-E-A_{L}(p n)$ hurrenkera ahozko hizkeratik desagertua zela iradokitzen duelako. Bigarren atalean erakutsiko

6 Bestelako egiturek ere, hots, baiezko perpausek eta aditz trinkoa daukaten ezezko perpausek ere, aldakortasuna erakusten dute euskararen historian zehar, baina horien bilakaeraren azterketa lan honen helmenetik kanpo dago. Horregatik (4a-f) moduko ezezko egitura perifrastikoak baizik ez dira izango hemendik aurrera aztergai. Ikerketa honetatik lekora gelditu dira, orobat, ezin izan aditz modala daramaten perpausak. Ez lokailutzat erabiltzen duten perpausak ere, hau da, Ez lanik egiten $d u$, ez lanik egiten uzten du-ren modukoak, eztabaidatik at utzi dira, aparteko hitz-hurrenkera baitute (Altuna, 2004, 104. or., 102. oin oharra).

7 Ezin da baztertu, beste alde batetik, Lardizabalek (1856) erabiltzen duen $\mathrm{A}_{\mathrm{N}}-\mathrm{E}-\mathrm{A}_{\mathrm{L}}$ (pn) hurrenkera zuzenean Larramendirengandik (1729) hartua delako susmoa, lehena pasarte askotan bigarrenaren hitzez hitzeko kopia baita (Mitxelena, 1978, 224. or.). Honek Lardizabalen adibideen balioa zalantzan jartzen du. 
denez, gizaldi horren erdialdetik aurrera $A_{N}-E-A_{L}(p n)$ hurrenkera oso gutxitan ikusten da, baina autore batzuek erabiltzen dute, eta ezin da guztiz baztertu, beraz, garai horretan oraindik ere erabiltzen zelako ustea. Beste alde batetik, Lakarrak $(1986,655)$ dio, bizkaiera zaharraren ezaugarri bereziak eztabaidatzean, euskalki honetan $A_{N}-E-A_{L}(p n)$ hurrenkera lekukotuta dagoela, baina $E-A_{L}-A_{N}(p n)$ askoz ere ohikoagoa dela. $A_{N}-E-A_{L}$ (pn) hurrenkera zinez ohikoa da bizkaiera zaharreko testuetan, Lakarrak berak ematen dituen adibideek erakusten duten moduan $(6 a-b)$. Alabaina, $E-A_{L}-A_{N}(p n)$ ordena ere garai eta euskalki bereko testuetan agertzen da $(6 c-d)$, bai eta $A_{N}-E-A_{L}(p n)$ hurrenkera garai bereko beste euskalkietan ere (6e-f):

(6) a. Lagun esteyo guerrara (1688; Lakarra, 1984, 120. or.)

b. Galdu çe eguic aldia ta ydoro dayc naya (1596; Lakarra, 1996, 330. or.)

c. Aranguiño estau ondo arguitu (Micoleta, 1653; Fita, 1897, 22, 30)

d. Basuac beste acayti estaude gausaric eguiten artez (Micoleta, 1653; Fita, 1897, 22. or.)

e. Egun hartan gal ezquiten aycinetic veguira (Etxepare, 1545; Altuna, 1980, 48. or.)

f. $\quad$ Niorc ere esanen estu ni<c> estudan partiduric (Amendux, 1564; Mitxelena, 1964, 108. or.)

Adibide hauek ikusirik, ez dirudi $\mathrm{A}_{\mathrm{N}}-\mathrm{E}-\mathrm{A}_{\mathrm{L}}(\mathrm{pn})$ hurrenkera bizkaiera zaharraren ezaugarri berezia denik. Hala ere, hurrenkera honen erabilera eta galera euskalkiaren arabera aldatzen ote diren egin daitekeen galdera da; bigarren atalean helduko zaio berriz honi. Lakarrak (1996, 254-255. or., 18. oin oharra) dio ezezko perpausetako $A_{N}-E-A_{L}$ hurrenkera esaldi positiboak oinarri hartuta sortu zela, eta gero $\mathrm{E}-\mathrm{A}_{\mathrm{L}}-\mathrm{A}_{\mathrm{N}}$ bilakatu zela: "[D]iakronikoki oinarrizko ordena positibokoa izanik (Ad. Nag - Ad. Lag.), hortik negatiboarena sortu (Ad. Nag. - EZ - Ad. Lag.) eta beranduago berrantolatu dela baitirudi (EZ - Ad. Lag. / - Ad. Nag.)». Baieztapen honek iradokitzen du $\mathrm{A}_{\mathrm{N}}-\mathrm{E}-\mathrm{A}_{\mathrm{L}}$ hurrenkera $\mathrm{E}-\mathrm{A}_{\mathrm{L}}-\mathrm{A}_{\mathrm{N}}$ baino zaharragoa dela, bai perpaus nagusietan bai mendekoetan. Reguero-Ugartek (2013, 434. or.) ere hala uste du: «[A]nother word order is also found with periphrastic verbs, which seems to be older».

Donemiliagako glosa $(4 \mathrm{~d}) \mathrm{A}_{\mathrm{N}}-\mathrm{E}-\mathrm{A}_{\mathrm{L}}(\mathrm{pn})$-ren adibidetzat hartzeak ez du esan nahi $E-A_{L}-A_{N}(p n)$ ordena berriagoa dela. Lehen testu luzeetan bai (4a-b) eta bai (4c) motako hurrenkera lekukotuta dagoela kontuan izanik, datuetan bakarrik oinarrituta zaila da $E-A_{L}-A_{N}(p n)$ berria dela frogatzea. Berdin zaila da $E-A_{L}-A_{N}$ zaharra dela baieztatzea, Mitxelenak egiten duen bezala: «[E]z dute ikusiko que es, y siempre parece haber sido, la forma corriente de expresar la negación» (Mitxelena, 1978, 224. or.).

Beste alde batetik, hizkuntzaren ekonomia printzipioari jarraituz (Zipf, 1949, 1-2. or.), ideia bera adierazteko egitura formal bat baino gehiago izatea (kasu honetan, ezeztapena adierazteko bi hitz-hurrenkera, hots, $\mathrm{E}_{-} \mathrm{A}_{\mathrm{L}}-\mathrm{A}_{\mathrm{N}}$ eta $\mathrm{A}_{\mathrm{N}}-\mathrm{E}-\mathrm{A}_{\mathrm{L}}$ ) luxutzat ikus daiteke, hau da, giza hizkuntzak egin daitekeen ahalegin txikienarekin ahalik eta gehien komunikatzeko joera daukanez gero, sinkronikoki bi hitz-hurrenkera izateko arrazoia, segur aski, diakronikoki bata bestea ordezkatzen ari izatea izango da. Hartara, $A_{N}-E-A_{L}$ hurrenkera zahartzat hartuz gero, $E-A_{L}-A_{N}$ berritzailetzat eman 
beharko litzateke, eta alderantziz. Zentzu honetan, forma zaharra eta berritzailea luzaroan batera eta aldizka erabiltzea hizkuntza aldaketan espero izatekoa da (Kroch, 2001, 720. or.). Lan honen asmoa da $\mathrm{A}_{\mathrm{N}}-\mathrm{E}-\mathrm{A}_{\mathrm{L}}$ (pn) hurrenkera zaharra ote den argitzen laguntzea.

Laburbilduz, beraz, ikerketa honek ondoko lau galderen erantzuna bilatuko du: (1) Noiz galdu zen zehatz-mehatz $\mathrm{A}_{\mathrm{N}}-\mathrm{E}-\mathrm{A}_{\mathrm{L}}(\mathrm{pn})$ hurrenkera euskararen historian? (2) Zein faktorek baldintzatzen dute $E-A_{L}-A_{N}$ eta $A_{N}-E-A_{L}$ hurrenkeren arteko aldakortasuna? (3) Zer desberdintasun daude euskalkien artean $A_{N}-E-A_{L}(p n)$ hurrenkeraren erabilerari eta galerari dagokienez? (4) $\mathrm{A}_{\mathrm{N}}-\mathrm{E}-\mathrm{A}_{\mathrm{L}}$ hurrenkera $\mathrm{E}-\mathrm{A}_{\mathrm{L}}-\mathrm{A}_{\mathrm{N}}$ baino zaharragoa da?

\subsection{Ezeztapena perpaus nagusietan eta mendekoetan}

Aurreko ataletan erakutsi den moduan, ezezko egitura perifrastikoen hitz-ordena aldatu egiten da, perpausa nagusia edo mendekoa izan. Horregatik, egitura hauen diakronia aztertzen duen edozein ikerketak perpaus nagusien eta mendekoen artean bereizketa garbia egin beharko luke. Alabaina, perpaus nagusi eta mendeko azpimota asko dago, eta azpimota hauek kontuan ez hartzeak ikerketan xehetasun ugari galtzeko arriskua lekarke. Horregatik, perpaus nagusiei dagokienez, Euskaltzaindiaren (2002, 2. or.) lanaren ildo beretik, perpaus nagusi jokatuak eta jokatugabeak bereiziko dira, eta lehen taldearen barruan adierazpenezkoak (7a), agintezkoak (7b) eta galderazkoak $(7 \mathrm{c})^{8}$ :

(7) a. Escátzen eztut nic justicia erchía (Lizarraga, 1821; Apezetxea, 1983, 65. or.)

b. Nehor obraz hil etçacu (Suarez d'Aulan, 1740, 9. or.)

d. Cegaiti lauoi bardin on erechi ez derausteçu euren amoreetan? (Lazarraga, 1602; Bilbao et al., 2011, 28. or.)

Mendeko perpausekin hainbat sailkapen desberdin egiteko aukera dago. Mounolek (2011, 11. or., 9. oin oharra), adibidez, eta ikerketa erraztearren mendeko perpausekin bi multzo egiten ditu: $-(e) n$ atzizkia daramatenak lehenik, hots, erlatibozkoak eta kausazkoak, eta -la atzizkia daramatenak gero, hau da, osagarriak eta zirkunstantzialak. De Rijkek (1969, 330-334. or.) -la atzizkiak Aux(iliary) Movement blokeatzeari buruz dioena kontuan izanik, ezeztapenaren hurrenkera ikertzean ez dirudi ideia txarra denik -la daramaten perpaus guztiak alde batean eta gainerakoak bestean ezartzea. Hala ere, hemengoa bezalako ikerketa batean segur aski sailkapen bitarra orokorregia litzateke, eta xehetasun gehiegi geldituko lirateke aintzat hartu gabe.

Euskaltzaindiak (1999; 2005), bestalde, askoz ere banaketa finagoa egiten du, mendeko perpaus osagarriak, erlatiboak, konparaziozkoak, ondoriozkoak, baldintzazkoak,

8 Egitura perifrastikoak normalean jokatuak direnez, Euskaltzaindiak $(2002$, 2. or.) aipatzen dituen perpaus jokatugabeak ez dira aintzat hartu. Gainera, harridura perpausak kontuan eduki ahal izateko gutxiegitan agertzen dira ikerktutako corpusean, eta, beraz, hauek ere ikerketatik kanpo utzi dira. 
denborazkoak, helburuzkoak, kausazkoak, kontzesiozkoak eta moduzkoak (hamar guztira) bereizten baititu. Hau Mounolenaren (2011) parean oso sailkapen zehatza da, baina hainbat arrazoirengatik hemengoa bezalako ikerketa baten irismenetik kanpo dago horren banaketa fina egitea. Horrela bada, bitarteko konponbidetzat lau perpaus mota ohikoenak hartuko dira hemen kontuan: osagarriak (-la) (8a), erlatibozkoak (-en, zein(a), non) (8b), baldintzazkoak (ba-, baldin) (8c) eta kausazkoak (bait-, -lako, -gatik, ezen, zeren) (8d). Gainerakoak bestelako-tzat sailkatuko dira (nabiz (eta), harik eta, baizik (eta) etab.) (8e):

(8) a. Ni bezain gaizqui vicitudenac ez luqueala ni nagoen lecuan egon behar (Mikelestorena, 1751, 43. or.)

b. Dantzaan sartuten ez dirianac (Frai Bartolome, 1816, 69. or.)

c. Baldiñ sensuec uqitcen ezpadute eguia (Gazteluzar, 1686, 251. or.)

d. Ecen eztitie ikutzen bere escuac oguia iaten dutenean (Leizarraga, 1571; Linschmann \& Schuchardt, 1990, 336. or.)

e. $\quad$ Bekhaturic ez eguitecotz ardura behardu herioaz (Tartas, 1666, 13. or.)

Menderagailuei dagokienez, zeren, nahiz (eta), ezen, zeinalnon, harik eta, eta baizik (eta) partikuletatik bat daukan esaldi oro mendekotzat hartu eta goian adierazitako bost motetako batean sartu da, menderagailuaren arabera. Honen arrazoia da partikula hauek menderakuntza adierazten dutela, ez elkarketa (Garzia, 2014, 51. or., 28. oin oharra). Zeren partikula daramaten esaldietan maiz aditzak bait- edo -en hartzen du, eta horrelakoetan zeren menderagailutzat erabiltzen da (Euskaltzaindia, 1990, 178. or.). Ondorioz, bait- eta -en mendekotasun markatzat hartu dira.

Mendekotasunaren gaineko azken ohar gisa, euskarazko ezeztapenaren hurrenkera aldaketa eta galera hobeki ulertzen lagun lezakeen kontua aipatu beharra dago. Hizkuntza aldaketaren eta tipologiaren inguruko literaturan askotan esan izan da mendeko perpausak perpaus nagusiak baino gordetzaileagoak direla ${ }^{9}$, hau da, aldaketa perpaus nagusietan mendekoetan baino lehenago burutzen dela ${ }^{10}$, besteak beste hitzhurrenkeraren aldaketari dagokionez (Givón, 1979, 259-261. or.; Lightfoot, 1982, 154. or.; Hock, 1986, 332. or.; Frajzyngier, 1996, 165-173. or.; Matsuda, 1998, 2-3. or.; Bybee, 2002, 4-5. or.; Crowley \& Bowern 2010, 231. or.), baina baita analogiazko aldaketari (Matsuda, 1993, 20. or.), berranalisiari (Mitchell, 1956, 80-86. or.; Bybee

9 Ikerketa honetako datuak ulertzeko moduaren arabera, hitz-hurrenkera bat galtzea (kasu honetan $\mathrm{A}_{\mathrm{N}}-\mathrm{E}-\mathrm{A}_{\mathrm{L}}$ (pn)) berrikuntzatzat ikus daiteke, eta ondorioz hurrenkera bera mantentzea ezaugarri gordetzailetzat. Horrela bada, eta joera tipologikoari jarraikiz, euskaraz ere perpaus nagusiak berritzaileak direla esan daiteke, eta mendeko perpausak gordetzaileak (ikus 2. puntuko eztabaida).

10 Kontrako baieztapena ere, mendeko perpausak berritzaileak eta perpaus nagusiak gordetzaileak direlakoa alegia, egin da literaturan, batez ere hitz-hurrenkeraren aldaketari (Stockwell \& Minkova, 1991, 399-400. or.) eta pro-drop ezaugarriaren galerari (Axel, 2007, 307-314, 321-325. or.) dagokienez. Egia esan, eztabaidak dagoeneko hamarkada batzuk dituen arren, ez dago inondik inora itxita, eta hizkuntza gehiagotako datuak jaso ahala ondorioak eta orokortzeak aldatuz joango dira. Oraingoz, behintzat, mendeko perpausak gordetzaileak direla segurtatzeko datu gehiago daude, eta autore gehiagok hala onartu dute. 
et al., 1994, 230-231. or.) eta ezaugarri morfosintaktikoen galerari (Poplack, 1997, 293, 296-297. or.) begira ere. Mendeko perpausen gordetzailetasunak, beraz, gramatikaren alderdi frankori (morfologiari, morfosintaxiari, sintaxiari) eta hizkuntza aldaketa mekanismo gehienei (analogiari, berranalisiari, hedapenari, galerari) eragiten diela dirudi.

Izaera gordetzaile horren emaitza sinkroniko muturrekoena perpaus nagusietan eta mendekoetan hitz-hurrenkera desberdinak izatea da. Hau da, esate baterako, nederlanderaren eta hebreera biblikoaren kasua (Givón, 1977, 192. or.). Oro har, hortaz, mendeko perpausen gordetzailetasunak arealki, tipologikoki eta genetikoki lotuta ez dauden hizkuntzen sinkroniari aski eragiten diola ematen du. Hau eta aurreko ataleko adibideak ikusirik, interesgarria izan daiteke mendeko perpausen gordetzailetasuna euskararen garapenean aztertzea ${ }^{11}$.

\section{EZEZTAPENAREN HURRENKERA HISTORIAN ZEHAR}

\subsection{Ezeztapena literaturan}

Ikerketa honetako corpusa osatzeko XVI. mendetik XX.era idatzitako hainbat testu hartu dira. Gainera, hizkuntzaren lagina ahalik eta adierazgarriena izan dadin eta emaitzak objektiboak eta alderagarriak izan daitezen, hainbat generotako testuak eduki dira kontuan, euskalki nagusi guztietakoak ${ }^{12}$ : corpus honetan mendebaldeko eta erdialdeko euskaran, nafarreran, nafar-lapurteran eta zubereran idatzitako testuak dau$\mathrm{de}^{13}$. Azkenik, ezeztapenaren hurrenkeraren garapena garbiagoa izan dadin, testuak mendez mende banatuta ikertu dira, ondoko ataletan ikus daitekeen bezala.

11 Euskararen mendeko perpausen gordetzailetasuna lehenago ere aipatu da: ikus Aldai (2002, 262; 2015, 332) eta Mounole (2011, 11-12, 298, 340. oin oharra).

12 Hurrengo generoek eta testuek osatzen dute ikertutako corpusa: olerkiak (Etxepareren Linguae vasconum primitiae, Bertso bizkaitarrak, Cantica ezpiritualac, Dagerreren Othoitce eta cantica espiritualac, Lizarragaren Koplak, Euscaldunen eliz-cantac, Gallopen Vingt-cinq chansons populaires eta Lauaxetaren Bide barrijak), hitz laua (Axularren Guero), antzerkia (Jakes Oihenarteren Kaniko eta Belxitina), saiakera (Kardaberatzen Eusqueraren berri onac), saiakera erlijiosoa (Leizarragaren Catechismea, Beriainen Tratado de como se ha de oyr Missa, Tartasen Onsa hilceco bidia eta Arima penitentaren occupatione devotaq, Etxeberri Sarakoaren Lau-urdiri gomendiozco carta, edo guthuna, Suarez d'Aulanen Catichima, Ubillosen Christau doctriñ berri-ecarlea eta Frai Bartolomeren Euscal-errijetaco olgueeta), itzulpenak (Betolatzaren eta Otxoa de Arinen Doctrina christianak, Larregiren Testamen çaharreco eta berrico bistorioa, Bruneten Jesu Cristoren evanjelioa eta Arrueren Santa Genovevaren vicitza), legezko testuak (Laphurdico comitatearen adierazpena), gutunak, epaiketetan esandakoak eta bestelako testu laburrak (ikus atal bakoitza), esaera zahar bildumak (Refranes y sentencias), ipuinak eta eleberriak (Wentworth Websterren Euskal ipuinak, Muxika Egañaren Umientzako ipuyak, Coyosen Zubererazko istorioak eta Errose Bustintzaren Euskalerriko ipuñak,) eta olerki eta hitz lau nahasketa (Lazarragaren Eskuizkribua). Ez litzateke ahaztu behar, jakina, corpus honen ezaugarriek emaitzetan eragina izan dezaketela, hots, corpus handiagoa edo desberdina ikertzeak agian bestelako emaitzak sortuko lituzkeela.

13 Euskalkien banaketa Zuazoren (2008) arabera egin da. 


\subsubsection{Ezeztapena XVI. mendean}

Hitz hurrenkerari dagokionez, hasiera-hasieratik ezezko egitura perifrastikoen testigantzek aldakortasuna erakusten dute. Horrela, Lakarraren (1996, 254-255. or., 18. oin oharra) eta Reguero-Ugarteren $\left(2013,434\right.$. or.) aburuz berritzailea den $E-A_{L}-A_{N}$ ordena testu askotan dago lekukotuta, ondoko perpaus nagusietan (9a-h) ikus daitekeen moduan:

(9) a. Eçayz yxilduco ardancopa matela (1536; Maiora, 2011, 30. or.)

b. Estou oussyc eguinan soury hin er darstura eguy harm (Rabelais, 1542; Mitxelena, 1964, 148. or.)

c. Eceyn iaunec eztu nahi muthil gaixtoa eduqui (Etxepare, 1545; Altuna, 1980, 10. or.)

d. $\quad$ Ni emen nayzala eçuen scribatu bear berçeri (Juan de Irañeta, 1549; Mitxelena, 1964, 59-60. or.)

e. Ezta erran nahi botherea baduela (Leizarraga, 1571; Linschmann \& Schuchardt, 1990, 1293. or.)

f. Batez ere arreposturic ezticit vqhven (Beltran d'Echaux, 1584; Mitxelena, 1964, 155. or.)

g. Hao ysian eztoa sartu eullia, ta aldi guztietan ezta eder eguia (1596; Lakarra, 1996, 280. or.)

h. Ydi çarrari çe eguioc alauneric sorosi (1596; Lakarra, 1996, 288. or.)

Hurrengo adibideek erakusten dute $E-A_{L}-A_{N}$ hurrenkera, perpaus nagusietan baino gutxiagotan agertzen bada ere, hasieratik mendeko perpausetan ere ez dela arraroa (10a-c):

(10) a. Ceren eztu eçagucen hala hongui eguina (Etxepare, 1545; Altuna, 1980, 130. or.)

b. Eta deus eztela eguiten harçaz baicen (Leizarraga, 1571; Linschmann \& Schuchardt, 1990, 1296. or.)

c. Erran draut eçela aren echetic alaco despachuric probeytu (1598; Maiora, 2011, 106. or.; Santazilia, 2015, 129-130. or.)

Hala ere, esan beharra dago batez ere gizaldi honetan $A_{N}-E-A_{L}$ hurrenkera nahiko hedatuta dagoela, hurrengo adibideetako perpaus nagusietan (11a-g) ikusten den bezala. Gainera, hitz-ordena hau adierazpenezko (11a-c, f) nahiz aginterazko (11d-e, g) esaldietan aurki daiteke:

(11) a. Esquer hon bat vqhen eztut çuyeganic vician (Etxepare, 1545; Altuna, 1980, 64. or.)

b. Niorc ere esanen estu ni<c> estudan partiduric (Amendux, 1564; Mitxelena, 1964, 108. or.)

c. Valizco oleac burniaric eguin eçtaroa (1571; Garibai, 1854)

d. Echiezeyguçu jausten tentaciñoan (Betolatza, 1596; Arana-Martija, 1986, 3. or.)

e. Çagoquez exilic ta ençun eztayçu guextoric (1596; Lakarra, 1996, 254. or.)

f. Iazquereac parrahua eguite ez du (1596; Lakarra, 1996, 302. or.)

g. Emongo badeustaçu luzatu çe eguidacu (1596; Lakarra, 1996, 364. or.) 
Azkenik, $A_{N}-E-A_{L}$ hurrenkeraren testigantzak mendeko perpausetan ere aurkitzea erraza da (12a-e), bai erlatibozkoetan (12a, e), bai osagarrietan (12b), bai kausazkoetan (12d) eta bai bestelakoetan (12c) ere:

(12) a. Esango dabee yn bidiac aurqui esango bearr ez tirean gauçaac (1537; Sarasola, 1983, 98-99. or.)

b. Hora il daguien mendian guiçona idoro ez didila (1571; Garibai, 1854)

c. Asi dira, ta onegaz vrten daude beralan oñeztar barruangoac çein erre ez citeçan (1588; Mitxelena, 1964, 83. or.)

d. Pena eternea gorde ez cituelaco (Betolatza, 1596; Arana-Martija, 1986, 4. or.)

e. Apizetan eztina edarayté da (1596; Lakarra, 1996, 368. or.)

Hurrengo taulak XVI. mendeko corpusaren ikerketaren emaitzak erakusten ditu:

1. taula. Ezezko egitura perifrastikoak XVI. mendean

\begin{tabular}{|c|c|c|c|c|c|}
\hline Idazlana & Urtea & $\begin{array}{c}\mathrm{E}-\mathbf{A}_{\mathrm{L}}-\mathbf{A}_{\mathrm{N}} \\
(\mathbf{p n})\end{array}$ & $\begin{array}{c}A_{N}-E-A_{L} \\
(p n)\end{array}$ & $\underset{(\mathrm{m})}{\mathrm{E}-\mathbf{A}_{\mathrm{L}}-\mathbf{A}_{\mathrm{N}}}$ & $\begin{array}{c}A_{N}-E-A_{L} \\
(m)\end{array}$ \\
\hline Linguae vasconum & 1545 & $27(\%$ 62.8) & $16(\% 37.2)$ & $6(\% 22.2)$ & $21(\% 77.8)$ \\
\hline Gutunak, epaiketak ${ }^{14}$ & 1550 & $9(\% 81.8)$ & $2(\% 18.2)$ & $1(\% 50.0)$ & $1(\% 50.0)$ \\
\hline Catechismea & 1571 & $95(\% 99.0)$ & $1(\% 1.0)$ & $36(\% 42.4)$ & $49(\% 57.6)$ \\
\hline Doctrina christiana & 1596 & $0\left(\begin{array}{ll}\% & 0.0\end{array}\right)$ & $1(\% 100)$ & $0\left(\begin{array}{ll}\% & 0.0\end{array}\right)$ & $7(\% 100)$ \\
\hline Refranes y sentencias & 1596 & $8(\% 23.5)$ & $26(\% 76.5)$ & $0\left(\begin{array}{ll}\% & 0.0\end{array}\right)$ & $7(\% 100)$ \\
\hline \multicolumn{2}{|l|}{ Osotara } & $139(\% 75.1)$ & $46(\% 24.9)$ & $43(\% 33.6)$ & $85(\% 66.4)$ \\
\hline
\end{tabular}

Datuei begira, esanguratsua da XVI. gizaldiko testu batzuetan, Betolatzaren Doctrina christianan eta Refranes y sentenciasen adibidez, E- $\mathrm{A}_{\mathrm{L}}-\mathrm{A}_{\mathrm{N}}$ hurrenkeraren testigantzarik ez egotea ia, ez perpaus nagusietan ez mendekoetan. Leizarragaren Catechismean, berriz, kasik ez dago $\mathrm{A}_{\mathrm{N}}-\mathrm{E}-\mathrm{A}_{\mathrm{L}}$ (pn) hurrenkeraren lekukotasunik. Zentzu honetan, datu hauek Lakarraren $(1986,655)$ iradokizuna bermatzen dute: beste euskalkien parean $\mathrm{A}_{\mathrm{N}}-\mathrm{E}_{-} \mathrm{A}_{\mathrm{L}}(\mathrm{pn})$ hurrenkera bizkaiera zaharrean dagoela hedatuen XVI. mendeko testuetan. Nolanahi ere, (11a-b) eta (12a) adibideek gizaldi honetan $A_{N}-E-A_{L}$ hurrenkera beste euskalkietan ere erabiltzen zela erakusten dute.

14 (9-12) adibideetan emandako testigantzez gain, hurrengo perpausak izan dira kontuan gutunak, epaiketak atalean corpuseko estatistikak osatzeko orduan: "Avnque las causas principales eztitut scriviçen por buenos respettos» (1545; Mitxelena, 1964, 60. or.); "Batre eztici pagatu nahi vqven» eta "Lehiaz eztaraçut ezcribacen luçazago" (1584; Mitxelena, 1964, 155. or.); "Heure bician estuc trataçen falçuqueriatan bayce» (Pedro Martinez de Betolatza, 1596; Urrizola, 2007, 300. or.; Santazilia, 2015, 124. or.) eta «Es omen çen alcateen baytan firmatu» (1598; Maiora, 2011, 107. or.; Santazilia, 2015, 129130. or.). 


\subsubsection{Ezeztapena XVII. mendean}

Hurrengo gizaldian, XVII.ean, egoera bestelakoa da. Oraindik aldakortasun zerbait ikus badaiteke ere, $E-A_{L}-A_{N}$ hurrenkera ohikoago bihurtzen da, bereziki perpaus nagusietan (13a-h). E-A $\mathrm{A}_{\mathrm{L}}-\mathrm{A}_{\mathrm{N}}$ hitz-ordena, adierazpen perpausetan (13a-d, g-h) ez ezik, galdera perpausetan (13e-f) ere lekukotuta dago:

(13) a. Beronec bere ezteidio falta gueiago damari (Lazarraga, 1602; Bilbao eta beste, 2011, 69. or., 6. oin oharra)

b. Vorondateas eztu alacoac, sines escatcen (Beriain, 1621, 91. or.)

c. Beharriez baicen eztut hor carela sinhetzten (Etxeberri Ziburukoa, 1665, 51. or.)

d. Baina nic orai presenteon, eztut bat baicen eccarrico (Axular, 1643, 221. or.)

e. Cergatic ezaiz leheneco gogoan, eta sinhestean fin egotu? (Axular, 1643, 132. or.)

f. Eztoçu Paternosterrean, eta Aue Marian Iaungoicoagaz, eta bere ameagaz verba eguiten? (Kapanaga, 1656, 42. or.)

g. Ezta oraiño aditu çure haurretaric duela Iaincoac abandonatu (Gazteluzar, 1686, 32. or.)

h. $\quad$ Ez eban nay çeruac gura euquean pobluac (1688; Lakarra, 1984, 118. or.)

Mendeko perpausetan ere E- $\mathrm{A}_{\mathrm{L}}-\mathrm{A}_{\mathrm{N}}$ hurrenkeraren testigantza asko daude (14a-g), bai osagarrietan (14a, d), kausazkoetan (14b-c, f-g) eta baldintzazkoetan (14e):

(14) a. Bere bician oy ez ebela gente obaric topadu (Lazarraga, 1602; Bilbao eta beste, 2011, 83. or.)

b. Eta ezpayluque sartunay vere viotzean (Beriain, 1621, 126. or.)

c. $\quad$ Non sainduric baicen deus ezpaita sarcen (Haranburu, 1635, 54. or.)

d. Eztioela cigorrac minic eguinen (Axular, 1643, 305. or.)

e. Leguiaç ezpalu erran, ezteçala desira iniustoqui (Tartas, 1666, 28. or.)

f. Ezpaiçara etorcen demboran (Voltoire, 1684, 41. or.)

g. Ceren espiritu bat ezpaitate eracoux (1696; Belapeire, 1983, 54. or.)

Hala ere, $E-A_{L}-A_{N}$ ordenaren maiztasun honek ez du inondik inora esan nahi $A_{N}-E-A_{L}$ hurrenkeraren lekukotasunak gutxi direnik. Hurrengoak ordena honen perpaus nagusietako lekukotasunak dira (15a-f):

(15) a. Neure bician ecusi ez dot ayn gauça abisaduric (Lazarraga, 1602; Bilbao eta beste, 2011, 86. or.)

b. $\quad$ Nic eztaquit jauna, ni<c> ycusi ezaytut (1611; Sarasola, 1983, 108. or.)

c. Eta falta ez dira machetaq sorrotsaq (1619; Ulibarri, 2011, 368. or.)

d. Behiñere ichilduco ezta hequin ahoa (Etxeberri Ziburukoa, 1665, 195. or.)

e. Gauça gasqui irabaciac eguiten estute seculan etorcen fiñ onic (Voltoire, 1684, 13. or.)

f. $\quad$ Yzango esta ne[u]re ustean ain golpe segurua (1688; Lakarra, 1984, 117. or.) 
Azkenik, mendeko perpausetan $A_{N}-E-A_{L}$ hurrenkera ere aurki daiteke (16a-e), bai osagarrietan (16b), bai baldintzazkoetan (16c-d), bai kausazkoetan (16e) eta bai bestelakoetan (16a) ere:

(16) a. Cegaiti artu ez daiquean (Lazarraga, 1602; Bilbao et al., 2011, 79. or., 4. oin oharra)

b. Eztuela halaco guerlaric eta eguitecoric sentitcen (Axular, 1643, 479. or.)

c. Incoa ezpada giten asqui sarri gure socorritcera (Tartas, 1672, 40. or.)

d. Vizicea ezaguzen espadaue (1688; Lakarra, 1984, 117. or.)

e. Cerren Iaungoicoa apartadu ez da gorpucerean ez arimeaganic (1691; Sarasola, 1983, 151. or.)

Hurrengo taulak XVII. mendeko corpusaren ikerketaren emaitzak erakusten ditu:

2. taula. Ezezko egitura perifrastikoak XVII. mendean

\begin{tabular}{|l|c|r|r|r|r|}
\hline Idazlana & Urtea & \multicolumn{1}{|c|}{$\begin{array}{c}\text { E-A } \\
\left(\mathbf{L}-\mathbf{A}_{\mathbf{N}}\right.\end{array}$} & $\begin{array}{c}\mathbf{A}_{\mathbf{N}}-\mathbf{E}-\mathbf{A}_{\mathbf{L}} \\
(\mathbf{p n})\end{array}$ & $\begin{array}{c}\mathbf{E}_{\mathbf{L}}-\mathbf{A}_{\mathbf{L}}-\mathbf{A}_{\mathbf{N}} \\
(\mathbf{m})\end{array}$ & $\begin{array}{c}\mathbf{A}_{\mathbf{N}}-\mathbf{E}-\mathbf{A}_{\mathbf{L}} \\
(\mathbf{m})\end{array}$ \\
\hline Eskuizkribua & 1602 & $53(\% 60.9)$ & $34(\% 39.1)$ & $13(\% 29.5)$ & $31(\% 70.5)$ \\
\hline Tratado & 1621 & $39(\% 100)$ & $0(\% 0.0)$ & $26(\% 57.8)$ & $19(\% 42.2)$ \\
\hline Guero (I-XV) & 1643 & $171(\% 100)$ & $0(\% 0.0)$ & $75(\% 50.7)$ & $73(\% 49.3)$ \\
\hline Onsa bilceco bidia & 1666 & $154(\% 100)$ & $0(\% 0.0)$ & $125(\% 76.7)$ & $38(\% 23.3)$ \\
\hline Arima penitentaren & 1672 & $85(\% 98.8)$ & $1(\% 1.2)$ & $30(\% 81.1)$ & $7(\% 18.9)$ \\
\hline Eguia catholicac & 1686 & $188(\% 98.4)$ & $3(\% 1.6)$ & $89(\% 71.8)$ & $35(\% 28.2)$ \\
\hline Bertso bizkaitarrak & 1688 & $8(\% 72.7)$ & $3(\% 27.3)$ & $2(\% 66.7)$ & $1(\% 33.3)$ \\
\hline Osotara & & $698(\% 94.5)$ & $41(\% 5.5)$ & $360(\% 63.8)$ & $204(\% 36.2)$ \\
\hline
\end{tabular}

Datu hauek ikusita bi ondorio nagusi atera daitezke: alde batetik, $\mathrm{E}-\mathrm{A}_{\mathrm{L}}-\mathrm{A}_{\mathrm{N}}$ hurrenkera ohikoagoa da, XVI. mendearen aldean, batez ere perpaus nagusietan. Beste alde batetik, perpaus nagusietako $A_{N}-E-A_{L}$ hurrenkeraren galera dela eta, XVI. mendean ikus zitekeen joera are garbiagoa da XVII. gizaldian: mendebaldeko euskaran hurrenkera hau oraindik nahiko arrunta da, Lazarragaren Eskuizkribuan adibidez. Aldiz, ekialdeko euskalkietan ordena hori ia erabat desagertu da: Axularrek, Gazteluzarrek eta Tartasek ia ez dute erabiltzen, beren idazkiak nahiko luzeak diren arren. Datuek, beraz, goian aipatutako Lakarraren (1986, 655. or.) iradokizuna bermatzen dute.

\subsubsection{Ezeztapena XVIII. mendean}

Gizaldi honetan aurreko mendeko $E-A_{L}-A_{N}$ hurrenkera nagusitzeko joerak neurri batean atzera egiten duela ematen du. Halarik ere, artean ere $E-A_{L}-A_{N}$ da hitz-ordenarik arruntena, kasu hontan perpaus nagusietan (17a-g). Hurrenkera hau ohikoa da adierazpen perpausetan $(17 \mathrm{a}-\mathrm{d}, \mathrm{g})$ eta galderetan $(17 \mathrm{e}-\mathrm{f})$ :

(17) a. Escuarac eztu gambiaduraric hartu (Etxeberri Sarakoa, 1712; Urkixo, 1907, 43. or.) 
b. Orregatican ere nay izandu ez ceban aitaric izan ceguian lurrean (Otxoa de Arin, 1713, 26. or.)

c. Baña atricioac eztu au eguyten (Elizalde, 1735, 68. or.)

d. Ez alzaitú antústeac amildúco (Larramendi, 1747; Telletxea, 1990)

e. Animen salvacioagatic, cer ez degu eguin bear? (Kardaberatz, 176lb; Altuna \& Zulaika, 2004, 21. or.)

f. Jauna, ez digu ezer erosten? (Munibe, 1762; Altzibar, 1991, 253. or.)

g. Ordean Faraonec etçuen entçun eguiten citçaioen othoitz humila (Larregi, 1775, 121. or.)

Mendeko perpausetan ere $\mathrm{E}-\mathrm{A}_{\mathrm{L}}-\mathrm{A}_{\mathrm{N}}$ hurrenkeraren testigantzak ez dira gutxi (18a-e), hala nola baldintzazkoetan (18a-c), osagarrietan (18e) eta bestelakoetan (18d):

(18) a. Bainan gogoan eta bihotcetan duguna ez badugu eracusten hitcetan (Etxeberri Sarakoa, 1718; Bilbao, 2006, 332. or.)

b. Ezpadupagacen ebatsi duena (Elizalde, 1735, 57. or.)

c. Jaincoac emán ezpacizún Jesúsen biotzaréquico dezún jayerá hori (Larramendi, 1747; Telletxea, 1990)

d. Alaco moduz nun momenturic laburrena ez det galduco (1761; Kardaberatz, 1896, 72. or.)

e. Uste dut ez nazulà utcico ni galdurìc (Mendiburu, 1765, 200. or.)

Ezezko marka hasieran daukan hurrenkera ohikoena bada ere ere, honek ez du esan nahi XVIII. mendean $\mathrm{A}_{\mathrm{N}}-\mathrm{E}-\mathrm{A}_{\mathrm{L}}$ hurrenkera gutxitan kausitzen dela. Hurrengo adibideak perpaus nagusiak dira, bai adierazpenak (19a-d) eta bai galderak (19e):

(19) a. Guizonic aguerí eztá (Larramendi, 1729, 4. or.)

b. Gogoac ematen dizuna baicic eguiten ez dezu (Mendiburu 1747, 141. or.)

c. Ceruco doai, añ ugari Jaun onec eman naidizquitzunac, artcen ezdituzu (Kardaberatz, 176la, 336. or.)

d. Bestelako tratamenturik merezitzen ez dozu (Munibe, 1764; Altzibar, 1991)

e. Cer behar ez-citçaion gosta haren amudioari ume maite baten sacrificatcea? (Larregi, 1775, 221. or.)

Azkenik, $\mathrm{A}_{\mathrm{N}}-\mathrm{E}-\mathrm{A}_{\mathrm{L}}$ hurrenkera hainbat mendeko perpaus motatan aurki daiteke, besteak beste baldintzazkoetan (20a-b), osagarrietan (20c), erlatibozkoetan (20e) eta bestelakoetan $(20 \mathrm{~d})$ :

(20) a. Içaten ezbanaïz (1714; Urte, 1900, 154. or.)

b. Batbatetàn aditzen ezpadirá (Larramendi, 1747; Telletxea, 1990)

c. Seygarrena araguiazco beccaturic eguin estazagula (1749; Reguero-Ugarte, 2017, 149. or.)

d. Ucatuco ez didazulaco ustean (Mendiburu, 1765, 54. or.)

e. Vici bat secula acaba eztadiena (1780; Santazilia, 2016, 77. or.)

Hurrengo taulak XVIII. mendeko corpusaren ikerketaren emaitzak erakusten ditu: 
3. taula. Ezezko egitura perifrastikoak XVIII. mendean

\begin{tabular}{|c|c|c|c|c|c|}
\hline Idazlana & Urtea & $\begin{array}{c}\mathrm{E}-\mathbf{A}_{\mathrm{L}}-\mathbf{A}_{\mathrm{N}} \\
(\mathbf{p n})\end{array}$ & $\begin{array}{c}A_{N}-E-A_{L} \\
(p n)\end{array}$ & $\begin{array}{c}E-A_{L}-A_{N} \\
(m)\end{array}$ & $\begin{array}{c}A_{N}-E-A_{L} \\
(m)\end{array}$ \\
\hline Doctrina christiana & 1713 & 37 (\% 94.9) & $2(\% 5.1)$ & $14(\%$ 19.4) & $58(\% 80.6)$ \\
\hline Lau-urdiri gomendio & 1718 & $7(\% 100)$ & $0\left(\begin{array}{lll}\% & 0.0\end{array}\right)$ & $6(\% 17.6)$ & $28(\% 82.4)$ \\
\hline Catichima edo fedia & 1740 & $29(\% 72.5)$ & $11(\% 27.5)$ & $37(\%$ 61.2) & $23(\% 38.8)$ \\
\hline Gutunak eta abar ${ }^{15}$ & 1750 & $25(\% 92.6)$ & $2(\% 7.4)$ & $24(\%$ 60.0) & $16(\% 40.0)$ \\
\hline Eusqueraren berri o. & 1761 & $5(\% 25.0)$ & $15(\% 75.0)$ & $2(\% 15.4)$ & $11(\% 84.6)$ \\
\hline Testamen çaharreco & 1775 & $178(\% 100)$ & $0\left(\begin{array}{lll}\% & 0.0\end{array}\right)$ & $122\left(\begin{array}{ll}\% & 78.2\end{array}\right)$ & $34(\% 21.8)$ \\
\hline Christau doctriñ be & 1785 & $29(\% 74.4)$ & $10(\% 25.6)$ & $10(\% 21.7)$ & $36(\% 78.3)$ \\
\hline Laphurdico comitate & 1790 & $12(\% 100)$ & $0(\% \quad 0.0)$ & $6(\% \quad 60.0)$ & $4(\% 40.0)$ \\
\hline \multicolumn{2}{|l|}{ Osotara } & $322(\% 89.0)$ & $40(\% 11.0)$ & 221 (\% 51.4) & $209(\% 48.6)$ \\
\hline
\end{tabular}

Datuak ikusita argi dago Mitxelenak (1978, 223-224. or.) proposatzen duen 1750 eta 1850 arteko idazle herrikoien eta gramatikarien bereizketa XVIII. gizaldian oraindik ez dela garbia: hainbat idazlek agertzen dute perpaus nagusietako $\mathrm{A}_{\mathrm{N}}-\mathrm{E}-\mathrm{A}_{\mathrm{L}}$ hurrenkera, besteak beste Kardaberatzek, Larramendik, Otxoa de Arinek, Ubillosek eta Suarez d'Aulanek. Gainera, oro har $\mathrm{A}_{\mathrm{N}}-\mathrm{E}-\mathrm{A}_{\mathrm{L}}$ ordena XVII. gizaldian baino ohikoagoa da, baina ez XVI. mendekoa bezainbeste. Egia da, bestalde, beste idazle batzuek -tartean Etxeberri Sarakoa eta Larregi daude- ez dutela hurrenkera hau biltzen. Honek Iparraldean $A_{N}-E-A_{L}(p n)$ ordena gutxitan erabiltzen dela erakusten badu ere, bereziki Suarez d'Aulanen lanean agertzeak idarokitzen du $A_{N}-E-A_{L}(p n)$ hurrenkera ez dela bakarrik mendebaldeko euskararen ezaugarria, XVIII. mendean behintzat.

\subsubsection{Ezeztapena XIX. mendean}

Aurreko mendeekin alderatuta ikusten da $E-A_{L}-A_{N}$ hurrenkerak XIX. mendean atzera egin duela, ez aurrera. Hala ere, $E-A_{L}-A_{N}$ da ohikoena perpaus nagusietan (21a-e), hala nola adierazpenetan ( $21 \mathrm{~b}, \mathrm{~d}-\mathrm{e})$ eta galderetan $(21 \mathrm{a}, \mathrm{c})$ :

15 (20c, e) adibideetan emandako testigantzez gain, hurrengo perpausak izan dira kontuan gutunak eta abar atalean corpuseko estatistikak osatzeko orduan: "Cer da ansi, enzunle gueyenac erausi hura aditzen ezpadute?", "Icasi ez dutenen artean, botatze eztituzten andican bera", "Eztute icen obeagoric mereci», «Oyec utzi bear eztitugu» eta «Eztezu ayetan aurquituco» (Larramendi, 1747; Telletxea, 1990); «Ceren guardatu echitusten», "Bigarrena estaguigula iuramenturic banoqui», "Bosgarrena nior ill eztecegula», "Seygarrena araguiazco beccaturic eguin estazagula», "Zazpigarrena deusic ebatchi estezagula», "Zorcigarrena falso testimonioriq alsa estezagula", "Bedezigarrena berceren senarriq edo emasteriq desea estecegula» eta "Amargarrena berceren ontasuniq desea estecegula» (1749; Reguero-Ugarte, 2017, 360. or.); "Vici bat deus ere falta eztaquitana, trabajuric igare eztezana», "Eztuela irabazten asqui mantenaceco», "Eztuzu caimbere trabaju bear», «Eztiten gendeac gal», "Eztiten guisa contan pasageroac gal», «Eztiatequezu gueyago desea», "Eziaucuzun Jaungoicoac berce legueric eman», "Eztugularic usacen», "Ezitela sar contuan zure sierboequin", "Eztezazula juzga zure sierboac» eta beste hainbeste (1780; Santazilia, 2016, 76-96. or.). 
(21) a. Cegaitic auxe berau eztozue ceuroc gaitic uste izaten? (Añibarro, 1803, 33. or.)

b. Baina ez dau onec gueure bijotzetati quenduten alegrija eguijazcua (Frai Bartolome, 1816, 22. or.)

c. Norc bada eztu deseyetuco, deseyo ta aleguiñ guciequi alaco diche? ( $\quad$ 1850; Salaberri \& Urrizola, 2008, 265. or.)

d. Ez dute hunkituko hortakoz khilurik (Berjes, 1867, 1. or.)

e. Etzan ezer entzuten inguru ayetan (Artzak, 1894, 15. or.)

Ordena hau berau mendeko perpausetan ikus daiteke (22a-d), besteak beste osagarrietan (22a), baldintzazkoetan (22c), erlatibozkoetan (22d) eta bestelakoetan (22b):

(22) a. Ez dezala Jaincoac nai inoiz Belgiacoac buruac arrotzea (Mogel, 1802; Mahn, 1857, 51-52. or.)

b. $\quad$ Çouretaco baici ezteçan hasperenic eguin (Dagerre, 1823, 30. or.)

c. Ferdinanek ez balu ordenuan bertzela egin (Daskonagerre, 1870, 72. or.)

d. Zeñac ez dira izan sortuac odolez (Brunet, 1884, 4. or.)

Ezezko marka hasieran daraman hurrenkera XIX. gizaldian ohikoagoa izateak ez du esan nahi, hala ere, $A_{N}-E-A_{L}$ ordena gutxitan aurki daitekeenik. Horren adibide dira hurrengo perpaus nagusietako testigantzak (23a-f):

(23) a. Iguituco ez da ecertara (Mogel, 1802; Mahn, 1857, 47. or.)

b. Secúlan aditu eztá bat berére otói acuditu zaióna beñére (Lizarraga, 1821; Apezetxea, 1983, 30. or.)

c. Ecarri ez dituzu sagárrac (Lardizabal, 1856, 66. or.)

d. Jaungoicoác naigabe munduan iñorc ere gordetzen ez nau (Arrue, 1882, 13. or.)

e. Zeñen gana etorri nai ez dezute, bizia izan dezazuten? (Brunet, 1884, 5. or.)

f. Jaunaz oroitzen ez da (Campion, 1884, 231. or.)

Azkenik, $\mathrm{A}_{\mathrm{N}}-\mathrm{E}-\mathrm{A}_{\mathrm{L}}$ hurrenkera mendeko perpausetan ere ez da gutxitan aurkitzen, tartean erlatibozkoetan (24a), osagarrietan (24b), baldintzazkoetan (24d) eta bestelakoetan $(24 c)$ :

(24) a. Necesidadericbaga trabajace eztauenac ( $\approx 1800$; Salaberri, 2004, 538. or.)

b. Adizáze, causa aurquitzen eztudála (Lizarraga, 1821; Apezetxea, 1983, 95. or.)

c. Norc berac communiatcen ez duenean errealki (Anonimoa, 1846, 34. or.)

d. Aitortuko ezpanu biyotzik eznuke (Artzak, 1894, 11. or.)

Hurrengo taulak XIX. gizaldiko corpusaren ikerketaren emaitzak erakusten ditu: 
4. taula. Ezezko egitura perifrastikoak XIX. mendean

\begin{tabular}{|l|c|c|c|c|c|}
\hline Idazlana & Urtea & $\begin{array}{c}\mathbf{E}_{\mathbf{L}}-\mathbf{A}_{\mathbf{L}}-\mathbf{A}_{\mathbf{N}} \\
(\mathbf{p n})\end{array}$ & $\begin{array}{c}\mathbf{A}_{\mathbf{N}}-\mathbf{E}-\mathbf{A}_{\mathbf{L}} \\
(\mathbf{p n})\end{array}$ & $\begin{array}{c}\mathbf{E}-\mathbf{A}_{\mathbf{L}}-\mathbf{A}_{\mathbf{N}} \\
(\mathbf{m})\end{array}$ & $\begin{array}{c}\mathbf{A}_{\mathbf{N}}-\mathbf{E}_{\mathbf{L}} \\
(\mathbf{m})\end{array}$ \\
\hline Cantica izpiritualac & 1804 & $16(\% 100)$ & $0(\% 0.0)$ & $2(\% 50.0)$ & $2(\% 50.0)$ \\
\hline Euscal-errijetaco o. & 1816 & $86(\% 90.5)$ & $9(\% 9.5)$ & $30(\% 28.8)$ & $74(\% 71.2)$ \\
\hline Lizarragaren Koplak & 1821 & $136(\% 81.4)$ & $31(\% 18.6)$ & $63(\% 58.3)$ & $45(\% 41.7)$ \\
\hline Othoitce eta cantica & 1823 & $38(\% 100)$ & $0(\% 0.0)$ & $18(\% 58.1)$ & $13(\% 41.9)$ \\
\hline Jesu Cristoren evan. & 1834 & $166(\% 96.5)$ & $6(\% 3.5)$ & $47(\% 48.5)$ & $50(\% 51.5)$ \\
\hline Kaniko eta Belxitina & 1848 & $64(\% 100)$ & $0(\% 0.0)$ & $21(\% 65.6)$ & $11(\% 34.4)$ \\
\hline Euskal ip. (1-110) & 1877 & $161(\% 100)$ & $0(\% 0.0)$ & $52(\% 76.5)$ & $16(\% 23.5)$ \\
\hline Santa Genovevaren & 1882 & $25(\% 23.4)$ & $82(\% 76.6)$ & $4(\% 9.5)$ & $38(\% 90.5)$ \\
\hline Osotara & & $692(\% 84.4)$ & $128(\% 15.6)$ & $237(\% 48.8)$ & $249(\% 51.2)$ \\
\hline
\end{tabular}

Datuek lehenbiziko begiradan erakusten dute XIX. mendean $A_{N}-E-A_{L}$ hurrenkera XVII. eta XVIII. mendeetan baino ohikoago bihurtu dela, perpaus nagusietan nahiz mendekoetan. Hala ere, idazleei begiratuz gero ikus daiteke joera honen erantzuleak bi autore direla: Lizarraga eta, batez ere, Arrue. Hauen lanak alde batera utziz gero, ikusten da $\mathrm{E}-\mathrm{A}_{\mathrm{L}}-\mathrm{A}_{\mathrm{N}}$ hurrenkera perpaus mota guztietan orokortu dela. Euskalkiei dagokienez, ez dago banaketa garbirik, $\mathrm{A}_{\mathrm{N}}-\mathrm{E}-\mathrm{A}_{\mathrm{L}}(\mathrm{pn})$ hurrenkera zaharra autore bizkaitarrek (Frai Bartolome), giputzek (Arrue, Brunet) eta nafarrek (Lizarraga) erabiltzen dutelako. Hori bai, Dagerrek eta Oihenartek hurrenkera hori bera ez erabiltzeak iradokitzen du $\mathrm{A}_{\mathrm{N}}-\mathrm{E}-\mathrm{A}_{\mathrm{L}}(\mathrm{pn})$ Iparraldean galdu zela lehenik.

\subsubsection{Ezeztapena XX. mendean}

Aurreko gizaldiko joerari jarraituaz, XX. mendearen lehen erdian $A_{N}-E-A_{L}(p n)$ hurrenkeraren azkeneko testigantzak ikus daitezke. Horrela, XX. gizaldiko corpusean autore gutxi batzuek baizik ez dute ibiltzen ordena hau: Lauaxetak (25c), Lopez de Mendizabal gramatikariak ( $25 \mathrm{~b}$ ) eta autore ezezagun batek (25a), adierazpen perpausetan (25b) nahiz galderetan (25a, c):

(25) a. Urricarriz biotza norc urratuco ez du? (Anonimoa, 1906, 4. or.)

b. Potoko esnea baño geiago estutzen ez da (Mendizabal, 1908, 134. or.)

c. Maitatzen eztozu? ${ }^{\text {16 }}$ (Lauaxeta, 1931, 57. or.)

16 Lauaxetak (1931, 57. or.) Maitatzen eztozu? hurrenkera darabil, baina hau metri causa egiten du: olerkiaren errima $x-a-x-a$ da, eta lerro honetako azken silabak $(-z u)$ bigarrenekoarekin errima egin dezan aditz laguntzaileak azken tokian joan behar du (Zer esaten dautzu ... Maitatzen eztozu). Idazleak hurrenkera markatugabea erabili balu (Eztozu maitatzen) errima hautsiko zuen. Horrela bada, adibide hau $\mathrm{A}_{\mathrm{N}}-\mathrm{E}_{-} \mathrm{A}_{\mathrm{L}}$ (pn) hurrenkeratzat hartzea zalantzazkoa da. 
Lopez de Mendizabalek (1908) $\mathrm{A}_{\mathrm{N}}-\mathrm{E}-\mathrm{A}_{\mathrm{L}}(\mathrm{pn})$ hurrenkera erabiltzen duela De Rijkek $(1969,333)$ eta Mitxelenak $(1978,224)$ aipatzen dute, baina ez, ordea, Lauaxetak (1931) eta autore ezezagunak (1906) gauza bera egiten dutela. Horregatik, XX. mendearen lehen erdian $A_{N}-E-A_{L}(p n)$ hitz-ordenaren erabilpena orain arte uste zen baino hedatuago zegoela esan daiteke. Egia da, hala ere, garai bereko idazle eta gramatikari gehienek gaur egungo euskaran ohikoa den $\mathrm{E}-\mathrm{A}_{\mathrm{L}}-\mathrm{A}_{\mathrm{N}}$ hurrenkera besterik ez dutela erabiltzen, perpaus nagusietan (26a-e):

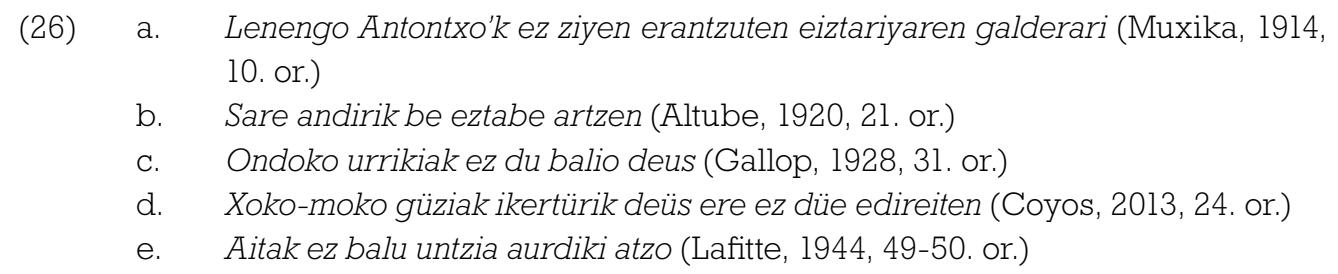

Hurrengo taulak XX. gizaldiko corpusaren ikerketaren emaitzak erakusten ditu:

5. taula. Ezezko egitura perifrastikoak Xx. mendean

\begin{tabular}{|c|c|c|c|c|c|}
\hline Idazlana & Urtea & $\begin{array}{c}\mathrm{E}-\mathbf{A}_{\mathrm{L}}-\mathbf{A}_{\mathrm{N}} \\
(\mathbf{p n})\end{array}$ & $\begin{array}{c}A_{N}-E-A_{L} \\
(p n)\end{array}$ & $\begin{array}{c}\mathrm{E}-\mathrm{A}_{\mathrm{L}}-\mathrm{A}_{\mathrm{N}} \\
(\mathbf{m})\end{array}$ & $\begin{array}{c}A_{N}-E-A_{L} \\
(m)\end{array}$ \\
\hline Euscaldunen eliz-cantac & 1906 & $41(\% 93.2)$ & $3(\% 6.8)$ & $6(\% 37.5)$ & $10(\% 62.5)$ \\
\hline Umientzako ipuyak & 1914 & $24(\% 100)$ & $0(\% 0.0)$ & $4(\% 26.7)$ & $11(\% 73.3)$ \\
\hline Vingt-cinq chansons & 1928 & $10(\% 100)$ & $0\left(\begin{array}{lll}\% & 0.0\end{array}\right)$ & $5(\% 83.3)$ & $1(\% 16.7)$ \\
\hline Bide barrijak & 1931 & $29(\% 93.5)$ & $2(\% 6.5)$ & $4(\%$ 66.7) & $2(\% 33.3)$ \\
\hline Zubererazko istorioak & 1939 & $181(\% 100)$ & $0\left(\begin{array}{lll}\% & 0.0\end{array}\right)$ & $64(\% 79.0)$ & $17(\% 21.0)$ \\
\hline Euskalerriko ipuñak & 1952 & $151(\% 100)$ & $0\left(\begin{array}{lll}\% & 0.0\end{array}\right)$ & $25(\% 39.7)$ & $38(\%$ 60.3) \\
\hline \multicolumn{2}{|l|}{ Osotara } & $436(\% 98.9)$ & $5(\% 1.1)$ & $108(\% 57.8)$ & $79(\% 42.2)$ \\
\hline
\end{tabular}

Perpaus nagusiei buruz aipatutakoez gain, datuei oharturik interesgarria da ikustea XX. mendean, XIX.aren aldean, mendeko perpausetan $E-A_{L}-A_{N}$ hurrenkera berriz ere ohikoago bihurtu dela. Gainera, euskalkien arabera joera garbia ikusten da: $A_{N}-E-A_{L}$ gehien erabiltzen duen euskalkia mendebaldekoa da, eta, kontrara, ekialdekoek $E-A_{L}-A_{N}$ hurrenkera nahiago dutela dirudi. Hau Lakarraren (1986, 655. or.) iradokizunarekin lotuz gero, pentsa liteke $\mathrm{A}_{\mathrm{N}}-\mathrm{E}-\mathrm{A}_{\mathrm{L}}$ lehenbizi Iparraldean eta ekialdean galdu zela perpaus nagusietan, segur aski XVIII. mendearen bukaeran edo XIX.aren hasieran, eta galera gero mendebalderantz hedatuz joan zela, $\mathrm{A}_{\mathrm{N}}-\mathrm{E}-\mathrm{A}_{\mathrm{L}}$ ordena XX. gizaldiaren hasieran guztiz lekutu arte. Kontu honi hurrengo atalean helduko zaio berriz.

\subsection{Ezeztapena: datuen interpretazioa}

Aurreko atalean XVI. eta XX. mendeen arteko ezezko egitura perifrastikoen bilakaera ikertu da, mendez mende. Atal honek, berriz, egitura horien garapenaren ikuspegi 
orokorra aurkeztuko du. Hurrengo grafikoek ezezko egitura perifrastikoen bilakaera erakusten dute, perpaus nagusietan (lehen grafikoa) eta mendeko perpausetan (bigarren grafikoa):

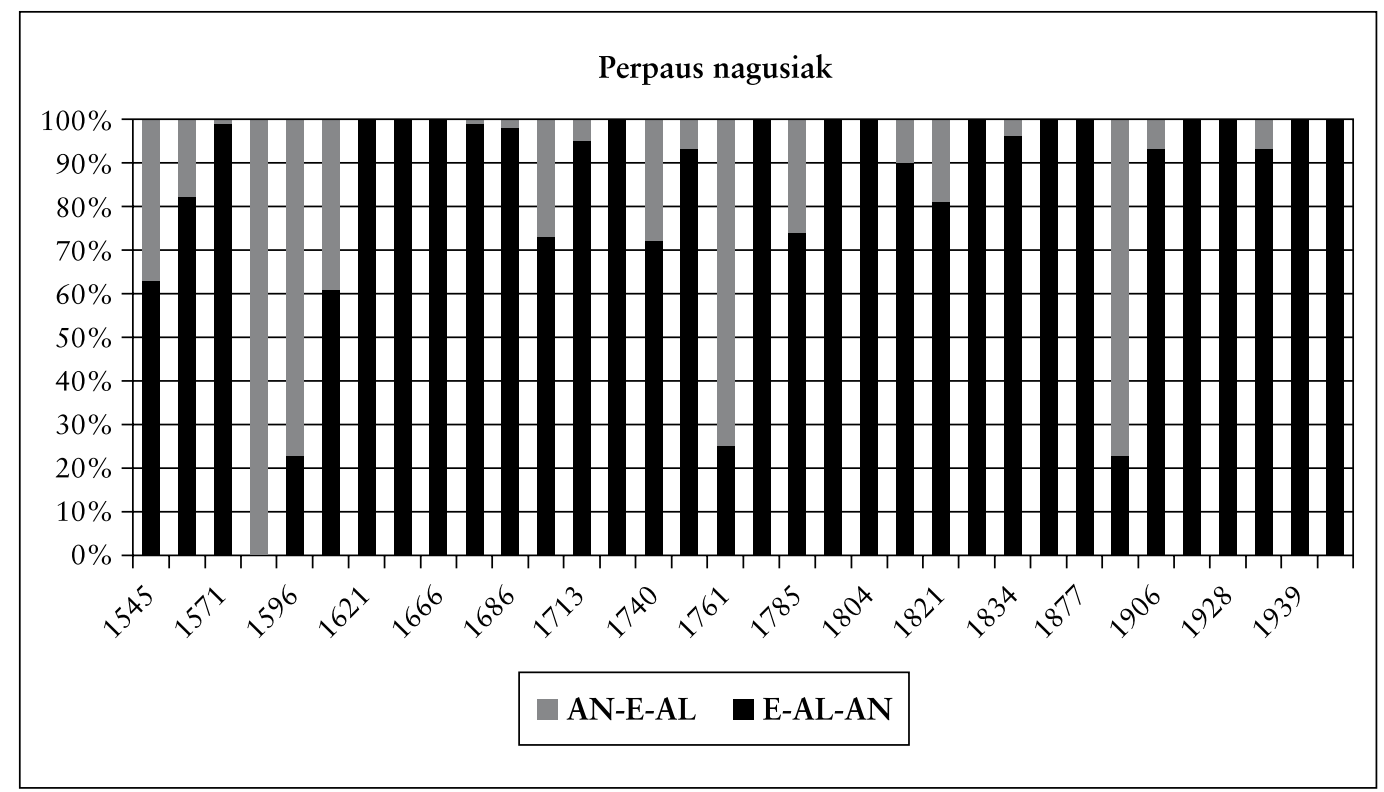

1. grafikoa. Ezezko egitura perifrastikoen hurrenkeraren garapena, perpaus nagusietan.

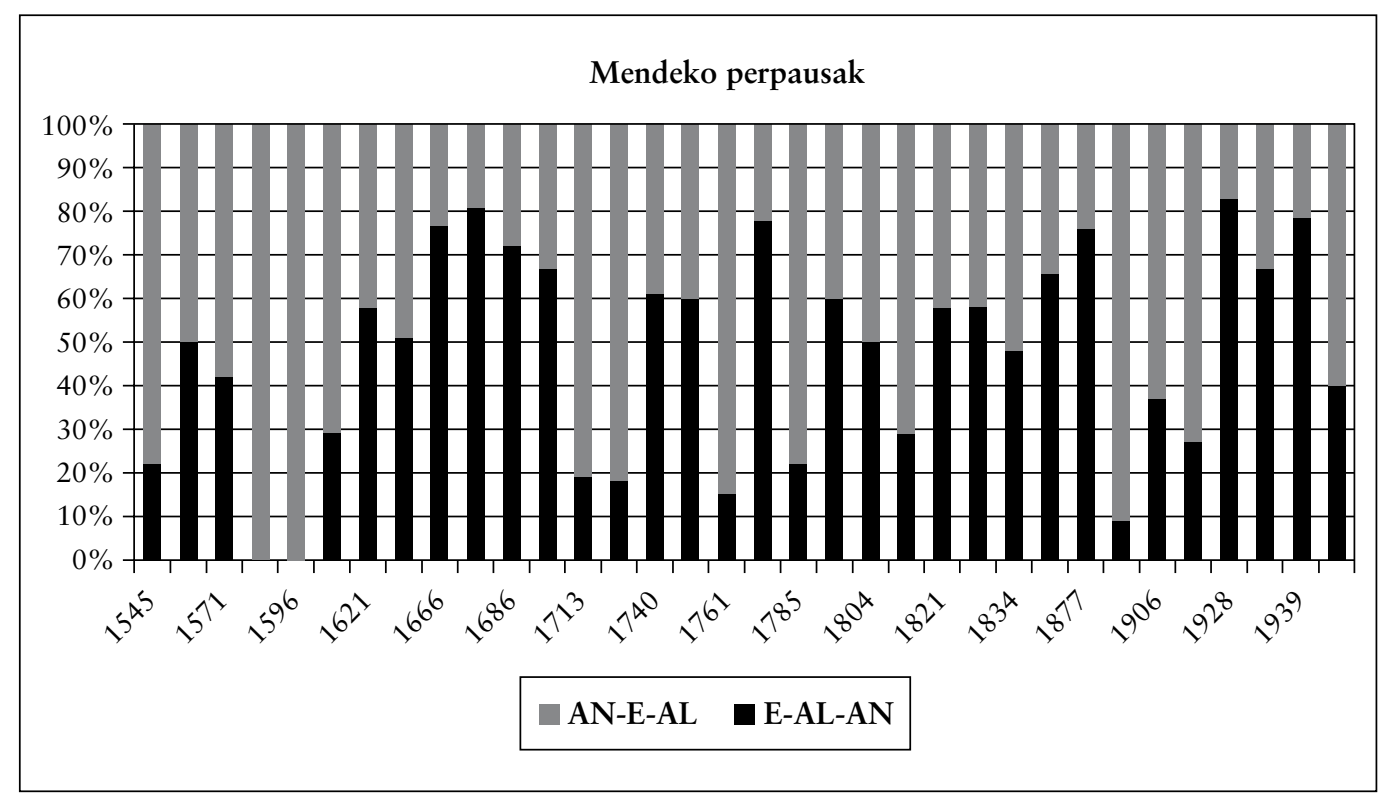

2. grafikoa. Ezezko egitura perifrastikoen hurrenkeraren garapena, mendeko perpausetan. 
Datuek erakusten duten bezala, euskararen historian zehar $A_{N}-E-A_{L}$ hurrenkera murriztu egin da, bai perpaus nagusietan eta bai mendekoetan ere. Perpaus nagusietan erabat galdu da, beranduenez XIX. gizaldiaren bukaerarako edo XX.aren hasierarako, antza. Hortaz, esan daiteke De Rijkek (1969, 330-334. or.) proposatutako Aux(iliary)Movement arau sintaktikoa garai honetarako bihurtu zela derrigorrezko, idatzizko hizkuntzan bederen: ahozkoan agian franko lehenago gertatuko zen hau ${ }^{17}$ (Mitxelena, 1978, 223-224. or.). Mendeko perpausek $A_{N}-E-A_{L}$ hurrenkera atxikitzea hainbat hizkuntzatan ikus daitekeen perpaus hauen gordetzailetasunaren bidez azal daiteke (Bybee, 2002, 4-5. or.), sarreran aipatu den bezala. Hala ere, badirudi E- $\mathrm{A}_{\mathrm{L}}-\mathrm{A}_{\mathrm{N}}$ ordenaren maiztasuna mendekoetan ere igo dela, batez ere Iparraldeko euskalkietan. Horregatik, espero izatekoa litzateke mendeko perpausek ere $A_{N}-E-A_{L}$ hurrenkera noizbait galtzea, eta, modu honetan, perpaus nagusietara lerratzea. Aldaketaren izaerari dagokionez, ez dirudi ezezko egitura perifrastikoen garapenak literaturan anitzetan proposatu den S-bihurguneko (S-curve, Sigmoid, S-shaped curve) aldaketa naturala jarraitzen duenik ${ }^{18}$ (Osgood \& Sebeok, 1954, 155. or.; Bailey, 1973, 77. or.; Kroch, 2001, 719. or.).

Hurrenkera bakoitzaren adinaren karietara, zenbakiek ez dute argitzen zaharrena zein den. $E-A_{L}-A_{N}$ perpaus nagusietan orokortzeak ordena hau berritzailea dela esan nahi duke, Lakarrak (1996, 254-255. or., 18. oin oharra) eta Reguero-Ugartek (2013, 434. or.) proposatzen duten moduan, baina hau ez da segurua, $E-A_{L}-A_{N}$ ordena lehen testuetarako oso ohikoa delako. Galdera honi ezin zaio, beraz, erantzun garbirik eman, oraingoz. Honek gelditzen diren bi galderetara gakartza: zein faktorek baldintzatzen dute hurrenkera bakoitzaren erabilera? Ba al dago euskalkien artean alderik erabilerari dagokionez?

\subsection{Ezeztapena zenbait faktoreren arabera}

\subsubsection{Perpaus mota}

Sarreran aipatu da perpaus mota desberdinak kontuan ez hartzeak xehetasun franko ez ikusteko arriskua izango lukeela. Horregatik, atal honetan ezezko egitura perifrastikoen hitz hurrenkera perpaus motaren arabera aztertuko da. Hurrengo taulak corpusaren ikerketaren emaitzak erakusten ditu, kasu honetan perpaus nagusi motaren arabera:

17 Datuei erreparaturik, ez dago garbi $\mathrm{A}_{\mathrm{N}}-\mathrm{E}-\mathrm{A}_{\mathrm{L}}(\mathrm{pn})$ hurrenkera ahozko eta idatzizko hizkuntzan aldi berean edo garai desberdinetan galdu zen. Galdera honi erantzuteko modu bat litzateke euskararen gramatika historikoetan, arauemaileetan batez ere, $\mathrm{A}_{\mathrm{N}}-\mathrm{E}-\mathrm{A}_{\mathrm{L}}(\mathrm{pn})$ hurrenkerari buruz esaten dena begiratzea. Gai hau oraingo lan honen helmenetik landa badago ere, etorkizunerako galdera interesgarria da.

18 Lan honen ebaluatzaile batek aipatu duen moduan, hau aldaketaren txandakatzeagatik izan daiteke: $\mathrm{A}_{\mathrm{N}}-\mathrm{E}-\mathrm{A}_{\mathrm{L}}(\mathrm{pn})$ ordenaren galera lehen testu luzeak agertu baino lehen, hots, XVI. mendearen aurretik hasi zela dirudi. Horrela bada, zenbakiek erakusten duten irudia ez da erabatekoa, aztertutako corpusaren ezaugarriek ere eragina izan baitezakete honetan. 
6. taula. Ezezko egitura perifrastikoak perpaus nagusi motaren arabera

\begin{tabular}{|l|c|c|}
\hline Perpaus nagusi mota & $\begin{array}{c}\text { E-A } \\
(\mathbf{L})\end{array}$ & $\begin{array}{c}\mathbf{A}_{\mathbf{N}}-\mathbf{E}-\mathbf{A}_{\mathbf{L}} \\
(\mathbf{p n})\end{array}$ \\
\hline Adierazpenak & $1848(\% 91.2)$ & $179(\% 8.8)$ \\
\hline Aginduak & $153(\% 66.5)$ & $77(\% 33.5)$ \\
\hline Galderak & $286(\% 98.6)$ & $4(\% 1.4)$ \\
\hline Denetara & $2287(\% 89.8)$ & $260(\% 10.2)$ \\
\hline
\end{tabular}

Datuek erakusten duten moduan, perpaus nagusi mota guztietan ikus daiteke $\mathrm{E}-\mathrm{A}_{\mathrm{L}}-\mathrm{A}_{\mathrm{N}}$ (pn) ordena orokortzeko joera. Salbuespen bakarra, agian, agintezko perpausak dira: kasuen heren batean $(77, \% 33.5)$ hurrenkera $A_{N}-E-A_{L}(p n)$ da. Salbuespen hau joera tipologikoen bitartez azal daiteke: hizkuntza askotan aginte perpausetan aditz nagusia perpausaren hasieran jartzen da, salbuespen ugari badaude ere (Aikhenvald, 2010, 9293. or.). Euskaraz ezezko aginte perpausek (edo, hobeki esan, debeku perpausek) bestelako perpausek baino neurri txikiagoan jasan dute aldaketa, aditz nagusia hasieran ezartzeko, hots, ikus ez ezazu bezalako ordena izateko, joera tipologikoa dela eta. Hau hurrengo adibideetan ikus daiteke (27a-c):

(27) a. Echiezeyguçu jausten tentaciñoan (Betolatza, 1596; Arana-Martija, 1986, 3. or.)

b. Nehor obraz hil etçacu (Suarez d'Aulan, 1740, 9. or.)

c. Iñor obraz illco ez dezu (Ubillos, 1785, 170. or.)

Adierazpen eta galdera perpausek, berriz, E- $\mathrm{A}_{\mathrm{L}}-\mathrm{A}_{\mathrm{N}}$ izateko joera garbia erakusten dute, bi perpaus motetan hurrenkera hau \% 90ean baino gehiagotan ikus baitaiteke. Ondoko taulak corpusaren ikerketaren emaitzak azaltzen ditu, kasu honetan mendeko perpaus motaren arabera:

7. taula. Ezezko egitura perifrastikoak mendeko perpaus motaren arabera

\begin{tabular}{|l|c|c|}
\hline Mendeko perpaus mota & $\begin{array}{c}\mathbf{E}_{\mathbf{L}}-\mathbf{A}_{\mathbf{N}} \\
(\mathbf{m})\end{array}$ & $\begin{array}{c}\mathbf{A}_{\mathbf{N}}-\mathbf{E}-\mathbf{A}_{\mathbf{L}} \\
(\mathbf{m})\end{array}$ \\
\hline Osagarriak & $482(\% 80.1)$ & $120(\% 19.9)$ \\
\hline Erlatibozkoak & $25(\% 7.7)$ & $300(\% 92.3)$ \\
\hline Baldintzazkoak & $152(\% 42.9)$ & $202(\% 57.1)$ \\
\hline Kausazkoak & $218(\% 82.3)$ & $47(\% 17.7)$ \\
\hline Bestelakoak & $92(\% 36.8)$ & $158(\% 63.2)$ \\
\hline Denetara & $969(\% 54.0)$ & $827(\% 46.0)$ \\
\hline
\end{tabular}

Datuek erakusten dute mendeko perpausen $A_{N}-E-A_{L}(m)$ hurrenkera gordetzeko joera perpaus motaren arabera asko aldatzen dela: alde batetik perpaus osagarriek (\% 80.1) eta kausazkoek (\% 82.3) $\mathrm{E}-\mathrm{A}_{\mathrm{L}}-\mathrm{A}_{\mathrm{N}}(\mathrm{m})$ hobesten dute. Beste aldetik, baldintzazkoek (\% 57.1), bestelakoek (\% 63.2) eta batez ere erlatibozkoek (\% 92.3) $\mathrm{E}-\mathrm{A}_{\mathrm{L}}-\mathrm{A}_{\mathrm{N}}$ ordena 
dute nahiago. Zentzu honetan jakina da egungo euskaran E- $A_{L}-A_{N}$ ordena erlatibozko perpausetan debekatuta dagoela (28b). Debeku honen arrazoia da horietan erlatiboaren marka aditz jokatuari (egitura perifrastikoetan, laguntzaileari) eratxiki behar zaiola eta aditz laguntzaileak perpausaren amaieran agertu behar duela (28a); E- $\mathrm{A}_{\mathrm{L}}-\mathrm{A}_{\mathrm{N}}$ hurrenkera erabiltzeak, aldiz, bi arau horiek betetzea galarazten du (28b) (Hualde \& Ortiz de Urbina, 2003, 767. or.):

\section{(28) a. Altubek kontutan hartu ez zuen oinarrizko partiketa batekin egin dut topo} b. $\quad *$ Altubek ez zuen kontutan hartu oinarrizko partiketa batekin egin dut topo ${ }^{19}$

Bistan da, beraz, erlatibozko perpausak bereziak direla hitz hurrenkerari dagokionez, bai gaurko euskaran, bai gaurdainokoan. Erlatiboak alde batera utziz gero, mendeko perpausen gordetzailetasuna ez da hain nabarmena: 527/1471-k (\% 35.8) daukate $\mathrm{A}_{\mathrm{N}}-\mathrm{E}-\mathrm{A}_{\mathrm{L}}(\mathrm{m})$ hitz-ordena.

\subsubsection{Euskalkia}

Aurreko ataletan iradoki da euskalkiak ere eragina izan lezakeela ezezko egitura perifrastikoen hitz hurrenkeraren aldaketan. Galdera honi erantzuteko asmoz, ondoko taulak ikertu diren XVI. gizalditik XX.era bitarteko testuen emaitzak biltzen ditu, euskalkiaren arabera sailkatuta:

8. taula. Ezezko egitura perifrastikoak euskalkiaren arabera

\begin{tabular}{|l|c|c|c|c|}
\hline Euskalkia & $\begin{array}{c}\mathbf{E}_{-\mathbf{A}_{\mathbf{L}}}-\mathbf{A}_{\mathbf{N}} \\
(\mathbf{p n})\end{array}$ & $\begin{array}{c}\mathbf{A}_{\mathbf{N}}-\mathbf{E}-\mathbf{A}_{\mathbf{L}} \\
(\mathbf{p n})\end{array}$ & $\begin{array}{c}\mathbf{E}_{\mathbf{L}}-\mathbf{A}_{\mathbf{L}}-\mathbf{A}_{\mathbf{N}} \\
(\mathbf{m})\end{array}$ & $\begin{array}{c}\mathbf{A}_{\mathbf{N}}-\mathbf{E}_{(\mathbf{A}} \mathbf{A}_{\mathbf{L}} \\
(\mathbf{m})\end{array}$ \\
\hline Mendebaldeko euskara & $335(\% 81.7)$ & $75(\% 18.3)$ & $74(\% 31.6)$ & $160(\% 68.4)$ \\
\hline Erdialdeko euskara & $513(\% 81.0)$ & $120(\% 19.0)$ & $163(\% 39.9)$ & $246(\% 60.1)$ \\
\hline Nafarrera & $184(\% 84.8)$ & $33(\% 15.2)$ & $90(\% 58.1)$ & $65(\% 41.9)$ \\
\hline Nafar-lapurtera & $771(\% 96.1)$ & $31(\% 3.9)$ & $402(\% 58.7)$ & $283(\% 41.3)$ \\
\hline Zuberera & $484(\% 99.8)$ & $1(\% 0.2)$ & $240(\% 76.7)$ & $73(\% 23.3)$ \\
\hline Denetara & $2287(\% 89.8)$ & $260(\% 10.2)$ & $969(\% 54.0)$ & $827(\% 46.0)$ \\
\hline
\end{tabular}

Datuek joera garbia erakusten dute: ekialdera joan ahala $\mathrm{A}_{\mathrm{N}}-\mathrm{E}-\mathrm{A}_{\mathrm{L}}$ gutxiagotan kausitzen da, perpaus nagusietan nahiz mendekoetan. Lakarraren (1986, 655. or.) eta Reguero-Ugarteren (2013, 434. or.) ildotik, eta Mitxelenaren $\left(1978,224\right.$. or.) aurka, E- $\mathrm{A}_{\mathrm{L}}-\mathrm{A}_{\mathrm{N}}$ ordena berritzailea dela pentsatzeak esan nahiko luke ekialdeko euskalkiak direla

19 Hizkera batzuetan analogiaz - $k o$ atzizkiarekin osatutako ezezko perpaus adberbialetara hedatzen da ezezko erlatibozko perpausen hitz-hurrenkera, hots, $\mathrm{A}_{\mathrm{N}}-\mathrm{E}-\mathrm{A}_{\mathrm{L}}(\mathrm{m})$. Horren ondorioz, aspaldidanik ikusi ez ditudan lagunak > aspaldidanik ikusieztako lagunak bezalako esaldiak osatzen dira (Txillardegi, 2005, 10. or.). Ematen duenez, hau berrikuntza da eta ez litzateke, arrazoi horrengatik, hemengo eztabaidarako kontuan hartu behar. 
berritzaileenak, eta mendebaldekoak berriz gordetzaileenak. Hau Ipar Euskal Herriko dialektoetan ikusten da garbienik: corpusean aztertu diren Iparraldeko egileetatik, $\mathrm{A}_{\mathrm{N}}-\mathrm{E}-\mathrm{A}_{\mathrm{L}}(\mathrm{pn})$ hurrenkera erabiltzen azkena Suarez d'Aulan da, XVIII. gizaldiaren erdialdean (1740). Hegoaldean, berriz, ordena hori erabiltzen azkena Lauaxeta (1931) da.

\section{ONDORIOAK}

Laburbilduz, lau galderari erantzuna emateko ahalegina egin da: $\mathrm{A}_{\mathrm{N}}-\mathrm{E}-\mathrm{A}_{\mathrm{L}}(\mathrm{pn})$ hurrenkera euskara idatzian XIX. mendearen bukaeran edo XX.aren hasiera aldean galdu zela erakutsi da; ezezko egitura perifrastikoen hitz ordenari perpaus motak eta euskalkiak eragiten diotela azaldu da, eta $\mathrm{A}_{\mathrm{N}}-\mathrm{E}-\mathrm{A}_{\mathrm{L}}(\mathrm{pn})$ hurrenkeraren galerari dagokionez, ekialdeko euskalkiak berritzaileenak eta mendebaldekoak gordetzaileenak direla aurkitu da. Kasu gehienetan ordena aldeak, debeku perpausetan eta mendekoetan adibidez, joera tipologikoengatik sortu direla iradoki da. Zoritxarrez, datuetan oinarrituta aztertutako bi hurrenkeren artean, hau da, $\mathrm{E}-\mathrm{A}_{\mathrm{L}}-\mathrm{A}_{\mathrm{N}}$ eta $\mathrm{A}_{\mathrm{N}}-\mathrm{E}-\mathrm{A}_{\mathrm{L}}$-ren artean, zaharrena zein den ezin izan da osotara argitu. Oro har, lan honetan egindako ekarpenek Lakarraren (1986; 1996) eta Reguero-Ugarteren (2013) baieztapenak berresten dituzte. Azkenik, Mitxelenak $(1978,224$. or.) proposatutako ahozko eta idatzizko euskararen arteko bereizketa etorkizuneko ikerketan aztertu beharko litzatekeen gaia dela aipatu da. 


\section{ERREFERENTZIAK}

Agirre, J. B. (1978). Confesioco, eta comunioco sacramentuen gañean eracusaldiak. Donostia: Hordago.

Aikhenvald, A. Y. (2010). Imperatives and commands. Oxford: Oxford University Press. Aldai, G. (2002). The grammaticalization of present and past in Basque (doktore tesia). University of Southern California, Los Angeles.

Aldai, G. (2015). Subordinadas completivas del verbo gertatu 'ocurrir' en Haraneder: ¿Subjuntivo extendido o conservación del aoristo perifrástico? FLV, 120, 327-344.

Altube, S. (1920). De sintaxis euskerica. Donostia: Imprenta de Martin, Mena y Compania.

Altzibar, X. (1991). Gabonsariak, El borracho burlado. Gasteiz: Eusko Legebiltzarra.

Añibarro, P. A. (1803). Lora-sorta espirituala, ta propositu santuac vicitza barri bat eguiteco. Tolosa: Don Francisco la Lama.

Anonimoa. (1846). Haurren liburua: meça eta besperac. Baiona: Cluzeau.

Anonimoa. (1906). Euscaldunen eliz-cantac. Bilbo: Villar.

Arana-Martija, J. A. (1986). Betolazaren «Doctrina christiana». Euskera 31, 2, 505 526.

Arrue, G. (1882). Santa Genovevaren vicitza. Tolosa: Pedro Gurrutxaga.

Artzak, A. (1894). Zerurá. Donostia: I. R. Baroja.

Axel, K. (2007). Studies on Old High German syntax. Left sentence periphery, verb placement and verb-second. Amsterdam/Philadelphia: John Benjamins.

Axular. (1643). Guero bi partetan partitua eta berecia. Bordele: G. Milanges.

Bailey, C. (1973). Variation and linguistic theory. Washington: Center for Applied Linguistics.

Belapeire, A. (1983). Catechima laburra eta Jesus-Christ goure ginco jaunaren eçagutcia, salvatu içateco (J. L. Davanten edizioa). Bilbo: Euskaltzaindia.

Beriain, J. (1621). Tratado de como se ha de oyr Missa, escrito en romance, y bascuence, lenguages de este obispado de Pamplona. Iruñea: Carlos de Labayen.

Berjes, J. (1867). Berxutako gudua Sarako bestan: lehembicico garhait-saria eraman duen kantua. Baiona: Lamaignère.

Betolatza, J. P. (1596). Doctrina christiana en romance y basquence. Bilbo: Pedro Cole de Ibarra.

Bilbao, G. (2006). Joanes Etxeberri Sarakoaren saiakera-lanak eta latina ikasteko gramatika: edizioa eta azterketa (doktore tesia). Gasteiz: Euskal Herriko Unibertsitatea.

Bilbao, G., Gómez, R., Lakarra, J. A., Manterola, J., Mounole, C. \& Urgell, B. (2011). Lazarraga eskuizkribua: edizioa eta azterketa (v. 1.2). Gasteiz: Euskal Herriko Unibertsitatea. http://www.ehu.eus/monumenta/lazarraga/index. html-tik aterea.

Brunet, F. (1884). Jesu Cristoren evanjelioa Juanen araura. Londres: Trinitarian Bible Society.

Bybee, J. (2002). Main clauses are innovative, subordinate clauses are conservative. Consequences for the nature of constructions. In J. Bybee (egilea) \& M. Noonan (arg.) Complex sentences in grammar and discourse: essays in 
honor of Sandra A. Thompson (1-17. or.). Amsterdam/Philadelphia: John Benjamins.

Bybee, J., Perkins, R. \& Pagliuca, W. (1994). The evolution of grammar: tense, aspect, and modality in the languages of the world. Chicago: University of Chicago Press.

Campion, A. (1884). Gramática de los cuatro dialectos literarios de la lengua euskara. Tolosa: Eusebio Lopez.

Chomsky, N. (1965). Aspects of the theory of syntax. Cambridge: MIT Press.

Chomsky, N., (1986). Knowledge of language: its nature, origin and use. New York: Praeger.

Coyos, J-B. (2013). Zubererazko istorio, alegia eta ipuin irri-egingarri. Bilbo: Euskaltzaindia.

Crowley, T. \& Bowern, C. (2010). An introduction to historical linguistics. Oxford: Oxford University Press.

Dagerre, R. (1823). Othoitce eta cantica espiritualac. Toulouse/Maule: Marchanta.

Daskonagerre, J.-B. (1870). Atheka gaitzeko oihartzunak. Baiona: Lamaignère.

De Rijk, R. P. G. (1969). Is Basque an SOV language?. FLV, 3, 319-351.

Elizalde, F. (1735). Apezendaco dotrina christiana uscáras. Iruñea: Alfonso Burguete.

Etxeberri Ziburukoa, J. (1665). Elicara erabiltceco liburua. Bordele: Mongiron Milang.

Etxepare, B. (1980). Linguae vasconum primitiae (P. Altunaren edizioa). Bilbo: Euskaltzaindia.

Etxepare, R. \& Uribe-Etxebarria, M. (2009). Hitz hurrenkera eta birregituraketa euskaraz. ASJU, 43, 335-356.

Euskaltzaindia. (1990). Euskal gramatika: lehen urratsak III (lokailuak). Bilbo: Euskaltzaindia.

Euskaltzaindia. (1999). Euskal gramatika: lehen urratsak V (mendeko perpausak 1). Bilbo: Euskaltzaindia.

Euskaltzaindia. (2002). Euskal gramatika laburra: perpaus bakuna. Bilbo: Euskaltzaindia.

Euskaltzaindia. (2005). Euskal gramatika: lehen urratsak VI (mendeko perpausak 2). Bilbo: Euskaltzaindia.

Frai Bartolome. (1816). Euscal-errijetaco olgueeta, ta dantzeen neurrizco-gatz-ozpinduba. Iruñea: Joaquin Domingo.

Frajzyngier, Z. (1996). Grammaticalization of the complex sentence: a case study in Chadic. Amsterdam/Philadelphia: John Benjamins.

Gallop, R. A. (1928). Vingt-cinq chansons populaires d'Eskual Herria. Baiona: Musée Basque.

Gazteluzar, B. (1686). Eguia catholicac salvamendu eternalaren eguiteco necessario direnac. Paue: Ioannes Desparatz.

Garibai, E. (1854). Refranes vascongados recogidos y ordenados por Estevan de Garibay y Camalloa. Madril: Jose Rodriguez. Faksmilie edizioa, Valentzia: Librerías «París-Valencia».

Garzia, J. (2014). Puntuazioa egoki erabiltzeko gida: oinarriak, jarraibideak eta aholkuak. Gasteiz: Eusko Jaurlaritza.

Givón, T. (1977). The drift from VSO to SVO in Biblical Hebrew: the pragmatics of tense-aspect. In C. N. Li (arg.), Mechanisms of syntactic change (181-254. or.). Austin/Londres: University of Texas Press. 
Givón, T. (1979). On understanding grammar. New York: Academic Press.

Goenaga, P. (1980). Gramatika bideetan (bigarren edizioa). Donostia: Erein.

Haranburu, J. (1635). Debocino escuarra mirailla eta oracinoteguia. Bordele: P. de la Covre.

Hock, H. H. (1986). Principles of historical linguistics. Berlin/New York: Mouton de Gruyter.

Hualde, J. I. \& Ortiz de Urbina, J. (2003). A grammar of Basque. Berlin/New York: Mouton de Gruyter.

Irigoien, A. (1975). Done Miliaga kukullakoa eta euskara. Euskera, 20, 161-194.

Kapanaga, M. O. (1656). Exposicion breue de la doctrina christiana (G. Lacomberen edizioa). Bilbo: Iuan de Azpiroz.

Kardaberatz, A. (1761a). Aita S. Ignacio Loyolacoaren egercicioac beren consideracio ta afectoaquin. Iruñea: A. Castilla.

Kardaberatz, A. (1761b). Eusqueraren berri onac (P. Altuna \& E. Zulaikaren edizioa). Bilbo: Euskaltzaindia.

Kardaberatz, A. (1896). Escu liburua ceñean dauden cristauaren eguneroco ejercicioac. Tolosa: Pedro Gurrutxaga.

Kroch, A. (2001). Syntactic change. In M. Baltin \& C. Collins (arg.), The handbook of contemporary syntactic theory (699-729. or.). Londres: Blackwell.

Lafitte, P. (1944). Grammaire basque (navarro-labourdin littéraire). Donostia: Elkar.

Laka, M. I. (1990). Negation in syntax: on the nature of functional categories and projections (doktore tesia). Massachussets Institute of Technology, Cambridge.

Laka, M. I. (1991). Sentence negation in Basque. In J. A. Lakarra \& I. R. Arzalluz (arg.), Memorice L. Mitxelena magistri sacrum, vol. 2 (899-926. or.). Donostia: Gipuzkoako Foru Aldundia.

Lakarra, J. A. (1984). Bertso bizkaitarrak (1688). ASJU, 18(2), 89-183.

Lakarra, J. A. (1986). Bizkaiera zaharra euskalkien artean. ASJU, 20(3), 639-682.

Lakarra, J. A. (1996). Refranes y sentencias (1596): ikerketak eta edizioa. Bilbo: Euskaltzaindia.

Lardizabal, F. I. (1856). Gramática vascongada. Donostia: Ignacio Ramón Barojaren imprimategia.

Lardizabal, F. I. (1908). Testamentu zar ta berrico condaira (E. Lopezen edizioa). Tolosa: Eusebio Lopez.

Larramendi, M. (1729). El imposible vencido: arte de la lengua bascongada. Salamanca: Antonio Joseph Villagordo Alcáraz.

Larregi, B. (1775). Testamen Çaharreco eta Berrico historioa. Baiona: Fauvet-Duhart.

Lauaxeta. (1931). Bide-barrijak: nuevos rumbos. Bilbo: Emeterio Verdes Achirica.

Leizarraga, I. (1990). Iesus christ gure iaunaren testamentu berria, othoitza ecclesiasticoen forma, catechismea, kalendrera, $A B C$ edo christinoen instructionea (T. Linschmann \& H. Schuchardten edizioa). Bilbo: Euskaltzaindia.

Lightfoot, D. (1982). The language lottery. Toward a biology of grammars. Cambridge: MIT Press.

Lizarraga, J. (1868). Jesucristoren evangelio sandua Juanec dacarran guisara (L. L. Bonaparteren edizioa). Londres: Strangeways \& Walden.

Lizarraga, J. (1983). Koplak (J. Apezetxearen edizioa). Bilbo: Euskaltzaindia. 
Mahn, C. A. F. (1857). Denkmäler der baskischen Sprache. Berlin: Ferdinand Duemmler. Maiora, F. (2011). Reino de Navarra, euskera: injurias, coplas, frases. Villatuerta: Fernando Maiora Mendia (egilea).

Matsuda, K. (1993). Dissecting analogical leveling quantitatively: the case of the innovative potential suffix in Tôkyô Japanese. Language Variation and Change, $5,1-34$.

Matsuda, K. (1998). On the conservatism of embedded clauses. Theoretical and applied linguistics at Kobe Shoin, 1, 1-13.

Mendiburu, S. (1747). Cer den, ta ceiñ ona Jesus-en Bihotzaren debocioa. Donostia: Bartholomé Riesgo Montero.

Mendiburu, S. (1765). Euscaldun onaren viciera. Iruñea: Martin Joseph Rada.

Mendizabal, I. (1908). Manual de conversación castellano-euskera. Tolosa: Eusebio Lopez.

Mikelestorena, J. (1751). Cerura nayduenac ardezaquean, vide erraza. Iruñea: Longás.

Mitchell, T. F. (1956). An introduction to Egyptian colloquial Arabic. Oxford: Clarendon Press.

Mitxelena, K. (1964). Textos arcaicos vascos. Madril: Ediciones Minotauro.

Mitxelena, K. (1978). Miscelánea filológica vasca I. FLV, 29, 205-228.

Mounole, C. (2011). Le verbe basque ancien: étude philologique et diachronique (doktore tesia). Euskal Herriko Unibertsitatea, Gasteiz.

Muxika Egaña, E. (1914). Antontxo (Gipuzkeraz): umientzako ipuyak. Bilbo: EuzkoGastedija.

Ortiz de Urbina, J. (1987). Operator movement and verb second phenomena in Basque. ASJU, 21(2), 321-355.

Osgood, C. \& Sebeok, T. (1954). Psycholinguistics: a survey of theory and research problems. Journal of Abnormal and Social Psychology, 49(4-2), 1-203.

Otxoa de Arin, J. (1713). Doctrina christianaren explicacioa. Donostia: Pedro de Ugarteren etxean.

Poplack, S. (1997). The sociolinguistic dynamics of apparent convergence. In G. R. Guy, C. Feagin, D. Schiffrin \& J. Baugh (arg.), Towards a social science of language, vol. 2. Social interaction and discourse structures (285-310. or.). Amsterdam/Philadelphia: John Benjamins.

Reguero-Ugarte, U. (2013). Word order. In M. Martínez-Areta (arg.), Basque and Proto-Basque. Language-internal and typological approaches to linguistic reconstruction (429-485. or.). Frankfurt am Main: Peter Lang.

Reguero-Ugarte, U. (2017). XVIII. mende erdialdeko Etxalarko dotrina. FLV, 124, 355 367.

Santazilia, E. (2015). Garai arkaikoko euskara nafarraren lekukotasun berriak: gehiketak eta zuzenketak F. Maioraren liburuari. FLV, 119, 109-146.

Santazilia, E. (2016). Zaraitzueraren lekukotasunak XVIII. mende bukaeran: hiru testu zahar eta autore berri bat. FLV, 121, 67-120.

Salaberri, P. (2004). Artatzako euskal testua: transkripzioa eta hizkuntza azterketa. FLV, 97, 537-554.

Salaberri P. \& Urrizola, R. (2008). Hiriberri Arakilgo predikuak I: transkripzioa eta azterketa. FLV, 108, 263-290. 
Sarasola, I. (1983). Contribución al estudio y edición de textos antiguos vascos. ASJU, 17, 69-212.

Stockwell, R. P. \& Minkova, D. (1991). Subordination and word order change in the history of English. In D. Kastovsky (arg.), Historical English syntax (367408. or.). Berlin/New York: Mouton de Gruyter.

Suarez d'Aulan, L. (1740). Catichima edo fediaren eta guiristino-eguien explicacione laburra. Paue: Dugue \& Desbaratz.

Tartas, J. (1666). Onsa bilceco bidia. Ortheze: Jacques Rovyer.

Tartas, J. (1672). Arima penitentaren occupatione devotaq. Ortheze: Jacques Rovyer.

Telletxea, J. I. (1990). Escritos breves: edición conmemorativa en el tercer centenario del nacimiento del P. Larramendi. Donostia: Argitalpen eta Publikapenen Gipuzkoar Erakundea.

Txillardegi. (2005). Labartzari agur. Donostia: Elkar.

Ubillos, J. A. (1785). Christau doctriñ berri-ecarlea. Tolosa: Francisco de la Lama.

Ulibarri, K. (2011). 1619. urtean Sevillan argitaraturiko bertsoak: cancion en lengua vascongada o vizcayna que contiene la sustancia deste sermon. ASJU, 45(1), 361-385.

Urkixo, J. (1907). Obras vascongadas del doctor labortano Joannes d'Etcheberry (1712). Paris: Paul Geuthner.

Urrizola, R. (2007). El euskera en Pueyo. FLV, 105, 299-302.

Urte, P. (1900). Grammaire cantabrique basque. Bagnères-de-Bigorre: Imprimerie D. Bérot.

Voltoire. (1684). Tresor des trois langues: françoise, espagnole et basque. Baiona: Paul Fauvet.

Zipf, G. K. (1949). Human behavior and the principle of least effort. An introduction to human ecology. Cambridge: Addison-Wesley Press.

Zuazo, K. (2008). Euskalkiak: euskararen dialektoak. Donostia: Elkar. 